\title{
Global Consensus Recommendations on Prevention and Management of Nutritional Rickets
}

\author{
Craig F. Munns Nick Shaw Mairead Kiely Bonny L. Specker Tom D. Thacher Keiichi Ozono \\ Toshimi Michigami Dov Tiosano M. Zulf Mughal Outi Mäkitie Lorna Ramos-Abad Leanne Ward \\ Linda A. DiMeglio Navoda Atapattu Hamilton Cassinelli Christian Braegger John M. Pettifor \\ Anju Seth Hafsatu Wasagu Idris Vijayalakshmi Bhatia Junfen Fu Gail Goldberg Lars Sävendahl \\ Rajesh Khadgawat Pawel Pludowski Jane Maddock Elina Hyppönen Abiola Oduwole \\ Emma Frew Magda Aguiar Ted Tulchinsky Gary Butler Wolfgang Högler
}

\section{Key Words}

Rickets · Nutrition · Vitamin D · Calcium · Consensus recommendations

\begin{abstract}
Background: Vitamin D and calcium deficiencies are common worldwide, causing nutritional rickets and osteomalacia, which have a major impact on health, growth, and development of infants, children, and adolescents; the consequences can be lethal or can last into adulthood. The goals of this evidence-based consensus document are to provide health care professionals with guidance for prevention, diagnosis, and management of nutritional rickets and to provide policy makers with a framework to work toward its eradication. Evidence: A systematic literature search examining the definition, diagnosis, treatment, and prevention of nutritional rickets in children was conducted. Evidence-based recommendations were developed using the Grading of Recommendations, Assessment, Development and Evaluation (GRADE) system that describes the strength of the recommendation and the quality of supporting evidence. Process: Thirty-three nominated experts in pediatric endocri-
\end{abstract}

nology, pediatrics, nutrition, epidemiology, public health, and health economics evaluated the evidence on specific questions within five working groups. The consensus group, representing 11 international scientific organizations, participated in a multiday conference in May 2014 to reach a global evidence-based consensus. Results: This consensus document defines nutritional rickets and its diagnostic criteria and describes the clinical management of rickets and osteomalacia. Risk factors, particularly in mothers and infants, are ranked, and specific prevention recommendations including food fortification and supplementation are offered for both the clinical and public health contexts. Conclusion: Rickets, osteomalacia, and vitamin D and calcium deficiencies are preventable global public health problems in infants, children, and adolescents. Implementation of international rickets prevention programs, including supplementation and food fortification, is urgently required.

ㄷ 2016 S. Karger AG, Basel and The Endocrine Society

See the Appendix for author affiliations.

This article is simultaneously published in The Journal of Clinical Endocrinology and Metabolism (DOI: 10.1210/jc.2015-2175).

\section{KARGER}

E-Mail karger@karger.com

www.karger.com/hrp
(C) 2016 S. Karger AG, Basel and The Endocrine Society $1663-2818 / 16 / 0852-0083 \$ 39.50 / 0$
Dr. Wolfgang Högler

Department of Endocrinology and Diabetes

Birmingham Children's Hospital, Steelhouse Lane

Birmingham B4 6NH (UK)

wolfgang.hogler@bch.nhs.uk 


\section{Summary of Consensus Recommendations ${ }^{1}$}

Section 1: Defining Nutritional Rickets and the Interplay between Vitamin D Status and Calcium Intake

1.1 Definition and Diagnosis of Nutritional Rickets

- Nutritional rickets (NR), a disorder of defective chondrocyte differentiation and mineralization of the growth plate and defective osteoid mineralization, is caused by vitamin $\mathrm{D}$ deficiency and/or low calcium intake in children. $(1 \oplus \oplus \oplus)$

- The diagnosis of NR is made on the basis of history, physical examination, and biochemical testing, and is confirmed by radiographs. $(1 \oplus \oplus \oplus)$

\subsection{Vitamin D Status}

- The panel recommends the following classification of vitamin $\mathrm{D}$ status, based on serum 25 -hydroxyvitamin D (25OHD) levels: $(1 \oplus \oplus \oplus)$

- Sufficiency, $>50 \mathrm{nmol} / \mathrm{l}$

- Insufficiency, 30-50 nmol/1

- Deficiency, $<30 \mathrm{nmol} / \mathrm{l}$

\subsection{Vitamin D Toxicity}

- Toxicity is defined as hypercalcemia and serum 25OHD $>250 \mathrm{nmol} / \mathrm{l}$, with hypercalciuria and suppressed parathyroid hormone (PTH). $(1 \oplus \oplus \oplus)$

\subsection{Dietary Calcium Intake to Prevent Rickets}

- For infants 0-6 and 6-12 months of age, the adequate calcium intake is 200 and $260 \mathrm{mg} /$ day, respectively. $(1 \oplus \oplus \oplus)$

- For children over 12 months of age, dietary calcium intake of $<300 \mathrm{mg} /$ day increases the risk of rickets independently of serum $25 \mathrm{OHD}$ levels. $(1 \oplus \oplus \bigcirc)$

- For children over 12 months of age, the panel recommends the following classification of dietary calcium intake: $(1 \oplus \oplus \bigcirc)$

- Sufficiency, >500 mg/day

- Insufficiency, 300-500 mg/day

- Deficiency, $<300 \mathrm{mg} /$ day

\subsection{Vitamin D Deficiency and Fractures}

- Children with radiographically confirmed rickets have an increased risk of fracture. $(1 \oplus \oplus \bigcirc)$

- Children with simple vitamin D deficiency are not at increased risk of fracture. $(1 \oplus \oplus \bigcirc)$

1 Grading of evidence: 1 = strong recommendation; 2 = weak recommendation. Quality of evidence: $\oplus \oplus \oplus=$ high; $\oplus \oplus \bigcirc=$ moderate; $\oplus \bigcirc \bigcirc=$ low quality.
Section 2: Prevention and Treatment of Nutritional Rickets and Osteomalacia

2.1 Vitamin D Supplementation for the Prevention of Rickets and Osteomalacia

- $400 \mathrm{IU} /$ day $(10 \mu \mathrm{g})$ is adequate to prevent rickets and is recommended for all infants from birth to 12 months of age, independently of their mode of feeding. $(1 \oplus \oplus \oplus)$

- Beyond 12 months of age, all children and adults need to meet their nutritional requirement for vitamin $\mathrm{D}$ through diet and/or supplementation, which is at least $600 \mathrm{IU} /$ day $(15 \mu \mathrm{g})$, as recommended by the Institute of Medicine (IOM). $(1 \oplus \oplus \oplus)$

\subsection{Target for Vitamin D Supplementation}

- In healthy children, routine $25 \mathrm{OHD}$ screening is not recommended, and consequently, no specific $25 \mathrm{OHD}$ threshold for vitamin $\mathrm{D}$ supplementation is targeted in this population. $(1 \oplus \oplus \oplus)$

\subsection{Candidates for Preventative Vitamin D}

Supplementation beyond 12 Months of Age

In the absence of food fortification, vitamin D supplementation should be given to:

- Children with a history of symptomatic vitamin D deficiency requiring treatment $(1 \oplus \oplus \oplus)$

- Children and adults at high risk of vitamin D deficien$\mathrm{cy}$, with factors or conditions that reduce synthesis or intake of vitamin $\mathrm{D}(1 \oplus \oplus \oplus)$

- Pregnant women (see section 3.1)

\subsection{Dose of Vitamin D and Calcium for the}

Treatment of Nutritional Rickets

- For the treatment of NR, the minimal recommended dose of vitamin $\mathrm{D}$ is $2,000 \mathrm{IU} /$ day $(50 \mu \mathrm{g})$ for a minimum of 3 months. $(1 \oplus \oplus \oplus)$

- Oral calcium, $500 \mathrm{mg} /$ day, either as dietary intake or supplement, should be routinely used in conjunction with vitamin $\mathrm{D}$ in the treatment regardless of age or weight. $(1 \oplus \oplus \oplus)$

\subsection{Appropriate Route of Administration and} Duration of Therapy

- We recommend oral treatment, which more rapidly restores $25 \mathrm{OHD}$ levels than intramuscular treatment. $(1 \oplus \oplus \oplus)$

- For daily treatment, both $\mathrm{D}_{2}$ and $\mathrm{D}_{3}$ are equally effective. $(1 \oplus \oplus \oplus)$

- When single large doses are used, $\mathrm{D}_{3}$ appears to be preferable compared to $\mathrm{D}_{2}$ because the former has a longer half-life. $(1 \oplus \oplus \oplus)$ 
- Vitamin D treatment is recommended for a minimum of 12 weeks, recognizing that some children may require a longer treatment duration. $(1 \oplus \oplus \oplus)$

\section{Section 3: Prevention of Nutritional Rickets/} Osteomalacia: Identification of Risk Factors

3.1 Dietary Practices and Nutrient Intakes among Mothers Associated with Nutritional Rickets in Infants

- Maternal vitamin D deficiency should be avoided by ensuring that women of childbearing age meet intakes of $600 \mathrm{IU} /$ day recommended by the IOM. $(1 \oplus \oplus \oplus)$

- Pregnant women should receive $600 \mathrm{IU} /$ day of vitamin $\mathrm{D}$, preferably as a combined preparation with other recommended micronutrients such as iron and folic acid. $(2 \oplus \oplus \bigcirc)$

3.2 Early Feeding, Supplementation, Complementary Feeding, and Nutrient Intake Associated with Rickets in Infants

- In addition to an intake of $400 \mathrm{IU} /$ day of vitamin D, complementary foods introduced no later than 26 weeks should include sources rich in calcium. $(1 \oplus \oplus \oplus)$

- An intake of at least $500 \mathrm{mg} /$ day of elemental calcium must be ensured during childhood and adolescence. $(1 \oplus \oplus \oplus)$

\subsection{Association of Sunlight Exposure with \\ Nutritional Rickets}

- Because ultraviolet B (UVB) rays trigger epidermal synthesis of previtamin $\mathrm{D}_{3}$, restricted exposure to sun increases the risk of vitamin $\mathrm{D}$ deficiency and NR. $(1 \oplus \oplus \oplus)$

- Environmental factors, such as latitude, season, time of day, cloud cover, and pollution affect the availability of UVB, whereas personal factors, such as time spent outdoors, skin pigmentation, skin coverage, age, body composition, and genetics affect the dose response of UVB exposure and circulating 25OHD. $(2 \oplus \oplus \bigcirc)$

- No safe threshold of UV exposure allows for sufficient vitamin $\mathrm{D}$ synthesis across the population without increasing skin cancer risk. $(2 \oplus \oplus \bigcirc)$

\section{Section 4: Prevention of Osteomalacia during} Pregnancy and Lactation and Congenital Rickets

4.1 The Relationship between Vitamin D during Pregnancy and Infant Growth and Bone Mass

- Pregnant women should receive 600 IU/day of supplemental vitamin $\mathrm{D}$. This will ensure adequacy of mater- nal $25 \mathrm{OHD}$, especially in women at risk of deficiency, to prevent elevated cord blood alkaline phosphatase (ALP), increased fontanelle size, neonatal hypocalcemia and congenital rickets, and to improve dental enamel formation. $(2 \oplus \oplus \bigcirc)$

- There is little evidence that maternal supplementation with vitamin $\mathrm{D}$ will protect or improve birth anthropometry $(2 \oplus \bigcirc \bigcirc)$ and no evidence that supplementation with vitamin $\mathrm{D}$ will protect or improve short- or long-term growth or bone mass accretion. $(2 \oplus \oplus \bigcirc)$

\subsection{The Effect of Calcium Supplementation during Pregnancy on Infant Bone Mass}

- Pregnant women do not need calcium intakes above recommended nonpregnant intakes to improve neonatal bone. $(1 \oplus \oplus \oplus)$

\subsection{Influence of Calcium or Vitamin D}

Supplementation in Pregnancy or Lactation on Breast Milk Calcium or Vitamin D

- Lactating women should ensure they meet the dietary recommendations for vitamin $\mathrm{D}$ (600 IU/day) for their own needs, but not for the needs of their infant. $(1 \oplus \oplus \oplus)$

- Lactating women should not take high amounts of vitamin $\mathrm{D}$ as a means of supplementing their infant. $(2 \oplus \oplus \bigcirc)$

- Pregnant and lactating women should meet the recommended intakes of calcium. Maternal calcium intake during pregnancy or lactation is not associated with breast milk calcium concentrations. $(1 \oplus \oplus \oplus)$

\subsection{Causes and Therapy of Congenital Rickets}

- Supplementing mothers with $600 \mathrm{IU} /$ day of vitamin D and ensuring they receive recommended calcium intakes, or appropriate therapy of maternal conditions predisposing to hypocalcemia or vitamin D deficiency, prevent congenital rickets. $(2 \oplus \bigcirc \bigcirc)$

Section 5: Assessing the Burden of Nutritional Rickets and Public Health Strategies for Prevention

5.1 Assessment of Disease Burden

- The prevalence of rickets should be determined by population-based samples, by case reports from sentinel centers, or by mandatory reporting. $(1 \oplus \oplus \oplus)$

- Screening for NR should be based on clinical features, followed by radiographic confirmation of suspected cases. $(1 \oplus \oplus \oplus)$

- Population-based screening with serum 25OHD, serum ALP, or radiographs is not indicated. $(1 \oplus \oplus \oplus)$ 
5.2 Public Health Strategies for Rickets Prevention

- Universally supplement all infants with vitamin D from birth to 12 months of age, independently of their mode of feeding. Beyond 12 months, supplement all groups at risk and pregnant women. Vitamin D supplements should be incorporated into childhood primary health care programs along with other essential micronutrients and immunizations $(1 \oplus \oplus \oplus)$, and into antenatal care programs along with other recommended micronutrients. $(2 \oplus \oplus \mathrm{O})$

- Recognize NR, osteomalacia, and vitamin D and calcium deficiencies as preventable global public health problems in infants, children, and adolescents. $(1 \oplus \oplus \oplus)$

- Implement rickets prevention programs in populations with a high prevalence of vitamin D deficiency and limited vitamin $\mathrm{D}$ and/or calcium intakes, and in groups of infants and children at risk of rickets. $(1 \oplus \oplus \oplus)$

- Monitor adherence to recommended vitamin D and calcium intakes and implement surveillance for NR. $(1 \oplus \oplus \oplus)$

- Fortify staple foods with vitamin D and calcium, as appropriate, based on dietary patterns. Food fortification can prevent rickets and improve vitamin $\mathrm{D}$ status of infants, children, and adolescents if appropriate foods are used and sufficient fortification is provided, if fortification is supported by relevant legislation, and if the process is adequately monitored. Indigenous food sources of calcium should be promoted or subsidized in children. $(1 \oplus \oplus \oplus)$

- Promote addressing the public health impact of vitamin D deficiency as both a clinical and a public health issue. $(1 \oplus \oplus \oplus)$

\subsection{Economic Cost/Benefits of Prevention Programs}

- The cost-effectiveness of supplementation and food fortification programs needs further study. $(1 \oplus \oplus \bigcirc)$ Nutritional rickets (NR), secondary to vitamin D deficiency and/or dietary calcium deficiency, remains a significant global, public health problem despite the availability of supplementation and numerous published guidelines for its prevention [1-8]. This is concerning because NR can have a major impact on the health of infants, children, and adolescents, with ramifications that persist into adulthood. The morbidity and mortality associated with NR can be devastating, with substantial but poorly recognized consequences for society and health economics. Features of NR and osteomalacia include: (1) hypocalcemic seizures and tetanic spasms; (2) life-threat- ening hypocalcemic cardiomyopathy; (3) bone pain and muscle weakness; (4) limb and pelvic deformities; (5) failure to thrive; (6) developmental delay, and (7) dental anomalies $[9,10]$. Alarmingly, NR can also lead to death from heart failure caused by hypocalcemic cardiomyopathy, even in developed countries [11]. In addition, narrowing of the pelvic outlet after NR in childhood can result in obstructed labor and maternal and fetal death [12].

Despite an intense focus around the role of vitamin D status in health and disease, there has been a worldwide failure to implement public health guidance and eradicate the severest manifestations of vitamin $\mathrm{D}$ and calcium deficiency in our most vulnerable population - NR and osteomalacia of childhood. Therefore, the goal of this Consensus Statement is to provide clinicians with clarity and recommendations on the recognition, societal burden, and treatment of NR and osteomalacia, and to enable clinicians and health policy leaders to establish appropriate clinical and public health interventions to prevent this debilitating, costly, and underrecognized global health problem.

\section{Methods}

In recognition of the considerable variation in the definition, diagnosis, and management of NR worldwide, the European Society for Pediatric Endocrinology decided to examine the current best practice in NR and to formulate evidence-based recommendations. Experts were assembled from the following societies: the Pediatric Endocrine Society (PES), the Asia Pacific Pediatric Endocrine Society (APPES), the Japanese Society for Pediatric Endocrinology (JSPE), the Sociedad Latino-Americana de Endocrinología Pediátrica (SLEP), the Australasian Pediatric Endocrine Group (APEG), the Indian Society for Pediatric and Adolescent Endocrinology (ISPAE), the African Society for Pediatric and Adolescent Endocrinology (ASPAE), the Chinese Society of Pediatric Endocrinology and Metabolism (CSPEM), the British Nutrition Society, and the European Society for Pediatric Gastroenterology, Hepatology and Nutrition (ESPGHAN). This consensus paper includes the cumulative evidence up to the end of 2014.

Participants included individuals from Europe, North America (United States and Canada), Latin America, Asia, Africa, and Australia, with a balanced spectrum of professional seniority and expertise. In addition, an expert on the development of evidencebased guidelines served in an advisory capacity. Panel members declared any potential conflict of interest at the initial meeting of the group. Thirty-three participants were assigned to one of five groups to which topics $1-5$ were allocated, and a chairperson was designated for each group. Each participant prepared an evidencebased summary of the literature relating to a particular question distributed before the conference (which was held over 3 days in May 2014).

Each group presented the revised summaries for discussion to the full conference. This report is based on the questions ad- 
dressed. A detailed description of the GRADE (Grading of Recommendations, Assessment, Development and Evaluation) classification has been published elsewhere [13]. Recommendations were based on published findings and on expert opinion when appropriate.

The best available research evidence was used to develop recommendations. Preference was given to articles written in English, identified by PubMed searches with MeSH terms. For each point, recommendations and evidence are described, with a modification in the grading evidence as follows: $1=$ strong recommendation (applies to most patients in most circumstances, benefits clearly outweigh the risk); 2 = weak recommendation (consensus opinion of working group or should be considered; the best action may depend on circumstances or patient values, benefits, and risks closely balanced or uncertain). Quality of evidence is indicated as follows: $\oplus \oplus \oplus=$ high quality [prospective cohort studies or randomized controlled trials (RCTs) at low risk of bias]; $\oplus \oplus \bigcirc=$ moderate quality (observational studies or trials with methodological flaws, inconsistent or indirect evidence); $\oplus \bigcirc \bigcirc=$ low quality (case series or nonsystematic clinical observations) [13].

The target audience for these guidelines includes general and specialist pediatricians, other professionals providing care for patients with NR, and health policy makers, particularly in countries with developing economies.

\section{Defining Nutritional Rickets and the Interplay between Vitamin D Status and Calcium Intake}

\subsection{Definition and Diagnosis of Nutritional Rickets \\ 1.1.1 Recommendations}

- NR, a disorder of defective chondrocyte differentiation and mineralization of the growth plate and defective osteoid mineralization, is caused by vitamin $\mathrm{D}$ deficiency and/or low calcium intake in children. $(1 \oplus \oplus \oplus)$

- The diagnosis of NR is made on the basis of history, physical examination, and biochemical testing and is confirmed by radiographs. $(1 \oplus \oplus \oplus)$

\subsubsection{Evidence}

Bone mineralization requires sufficient supply of the essential mineral ions, calcium and phosphate, with vitamin D optimizing their absorption from the gut. With insufficient serum calcium concentration caused by either vitamin $\mathrm{D}$ deficiency or inadequate dietary calcium intake, parathyroid hormone (PTH) will stimulate osteoclastic bone resorption to release stored bone minerals into the bloodstream and maintain normal serum calcium [14]. Bone disease (rickets and osteomalacia) develops once elevated PTH has led to low serum phosphate levels, as a result of impaired renal phosphate conservation [15].
Table 1. Clinical features associated with NR

\section{Osseous signs and symptoms}

Swelling wrists and ankles

Delayed fontanelle closure (normally closed by the age of 2 years)

Delayed tooth eruption (no incisors by the age of 10 months, no molars by 18 months)

Leg deformity (genu varum, genu valgum, windswept deformity)

Rachitic rosary (enlarged costochondral joints - felt anteriorly, lateral to the nipple line)

Frontal bossing

Craniotabes (softening of skull bones, usually evident on palpation of cranial sutures in the first 3 months)

Bone pain, restlessness, and irritability

\section{Radiographic features}

Splaying, fraying, cupping, and coarse trabecular pattern of metaphyses

Widening of the growth plate

Osteopenia

Pelvic deformities including outlet narrowing (risk of obstructed labor and death)

Long-term deformities in keeping with clinical deformities

Minimal trauma fracture

Nonosseous features

Hypocalcemic seizure and tetany

Hypocalcemic dilated cardiomyopathy (heart failure, arrhythmia, cardiac arrest, death)

Failure to thrive and poor linear growth

Delayed gross motor development with muscle weakness

Raised intracranial pressure

NR is a disorder of defective growth plate chondrocyte apoptosis and matrix mineralization in children. Osteomalacia is abnormal matrix mineralization in established bone, and although present in children with rickets, it is used to describe bone mineralization defects after completion of growth. Children with an underlying disease such as fat malabsorption, liver disease, renal insufficien$\mathrm{cy}$, and illnesses necessitating total parenteral nutrition can also develop NR and are briefly discussed in this review. NR does not include rickets associated with heritable disorders of vitamin D metabolism, including 1-ahydroxylase deficiency and vitamin $\mathrm{D}$ receptor defects, or congenital or acquired hypophosphatemic rickets.

The clinical features and consequences of NR are broad and potentially severe (table 1) [8]. Defective mineralization leads to radiographic growth plate widening as well as metaphyseal cupping and fraying, which confirm the diagnosis of NR.

Biochemical testing alone is not sufficient to diagnose NR and may not differentiate whether the primary cause 
of NR is vitamin D or dietary calcium deficiency because combined deficiencies are common. Typical laboratory findings in NR are decreases in 25-hydroxyvitamin D (25OHD), serum phosphorus, serum calcium, and urinary calcium. Conversely, serum PTH, alkaline phosphatase (ALP), and urinary phosphorus levels are invariably elevated $[10,16]$.

Vitamin D status is assessed by measuring blood levels of total $25 \mathrm{OHD}$. Total $25 \mathrm{OHD}$ is used, assuming that $25 \mathrm{OHD}_{2}$ and $25 \mathrm{OHD}_{3}$ are of equal biological value [16]. There is considerable variability between laboratory methods for measuring serum 25OHD concentrations [17]. Immunoassays are popular due to their convenience and high sample throughput; however, crossreactivity between vitamin $\mathrm{D}$ metabolites $\left[25 \mathrm{OHD}_{2}\right.$, $25 \mathrm{OHD}_{3}$, and $\left.24,25(\mathrm{OH})_{2} \mathrm{D}\right]$ and high levels of estimated bias in several automated assays cast doubt on their reliability, particularly at high and low concentrations of 25OHD [18]. Higher-order reference measurement procedures for serum 25OHD have been established by the National Institute of Standards and Technology (NIST) [19] and Ghent University [20] based on isotope dilution liquid chromatography-tandem mass spectrometry. In recent years, the accuracy of $25 \mathrm{OHD}$ assays has improved, also by activities of the Vitamin D Standardization Program [21], which aims to standardize the results of different measurement techniques to those of the reference measurement procedures [22]. Significant reductions in interlaboratory variation in serum $25 \mathrm{OHD}$ are observed using liquid chromatography-tandem mass spectrometry with the application of NIST standard reference materials [23].

Dietary calcium deficiency is diagnosed by obtaining a calcium intake history. Because the sources of calcium will vary by country and region, we recommend that clinicians develop a dietary calcium intake questionnaire specific to their country/region.

\subsection{Vitamin D Status}

\subsubsection{Recommendation}

- The panel recommends the following classification of vitamin D status, based on serum 25OHD levels: $(1 \oplus \oplus \oplus)$

- Sufficiency, $>50 \mathrm{nmol} / 1$

- Insufficiency, 30-50 nmol/1

- Deficiency, <30 nmol/l

\subsubsection{Evidence}

Our definition of vitamin D deficiency in the context of skeletal mineralization and mineral ion metabolism for the prevention of NR is based on strong evidence $[1,2$, 24-27] supported by the increased incidence of NR with $25 \mathrm{OHD}$ concentrations $<30 \mathrm{nmol} / \mathrm{l}(1 \mathrm{ng} / \mathrm{ml}=2.5 \mathrm{nmol} / \mathrm{l})$. Our definition is consistent with that of the Institute of Medicine (IOM) [28]. The potential health impacts of maintaining a serum concentration $>50 \mathrm{nmol} / \mathrm{l}$ are beyond the scope of this review and are addressed elsewhere [29]. It should be noted that NR has been reported in children with $25 \mathrm{OHD}$ concentrations $>30 \mathrm{nmol} / 1[2,5,6,30]$ and that NR may not occur with very low $25 \mathrm{OHD}$ concentrations but is more likely to occur with deficiency sustained over time, i.e. chronic deficiency. Most children with vitamin D deficiency are asymptomatic [15], highlighting the interplay between serum 25OHD level and dietary calcium intake in maintaining serum calcium concentrations and bone integrity (fig. 1).

Although the most significant functional outcome of vitamin $\mathrm{D}$ deficiency is the development of osteomalacia and NR, biochemical and bone density associations are also reported. Laboratory observations demonstrate that PTH increases when 25OHD levels drop below $34 \mathrm{nmol} / \mathrm{l}$ [7]. Moreover, all patients with NR in that study had $25 \mathrm{OHD}$ levels $<34 \mathrm{nmol} / \mathrm{l}$, and PTH was elevated in all but 1 patient. Taken together, the evidence suggests that a $25 \mathrm{OHD}$ level at 30-34 $\mathrm{nmol} / \mathrm{l}$ may be the critical cutoff below which NR is more likely to occur.

Seasonal variations in 25OHD of between 13 and 24 $\mathrm{nmol} / \mathrm{l}$ [31] emphasize the importance of maintaining $25 \mathrm{OHD}$ levels $>50 \mathrm{nmol} / \mathrm{l}$ (i.e. sufficient), so as to prevent prolonged periods of $25 \mathrm{OHD}$ levels $<30 \mathrm{nmol} / \mathrm{l}$, with the risk of developing NR.

\subsection{Vitamin D Toxicity}

1.3.1 Recommendation

- Toxicity is defined as hypercalcemia and serum $25 \mathrm{OHD}>250 \mathrm{nmol} / \mathrm{l}$ with hypercalciuria and suppressed $\mathrm{PTH}^{2} .(1 \oplus \oplus \oplus)$

\subsubsection{Evidence}

Intoxication is predominantly seen in infants and young children after exposure to high doses of vitamin D (240,000-4,500,000 IU) [32-37]. High 25OHD concentrations can cause hypercalcemia, hypercalciuria, and, if prolonged, nephrocalcinosis and renal failure. To allow a

\footnotetext{
2 In areas where 25OHD assays are not readily available, suppression of PTH in the presence of hypercalcemia and pharmacological doses of vitamin $\mathrm{D}$ may support the diagnosis of vitamin D toxicity. When a PTH assay is also unavailable, the possibility of toxicity should be considered in the presence of symptomatic hypercalcemia in association with pharmacological doses of vitamin D.
} DOI: $10.1159 / 000443136$
Munns et al. 
Fig. 1. Biochemical disturbances in rickets pathogenesis based on a three-stage classification of vitamin D status (symbolized by the sun) and calcium intake (symbolized by a glass of milk). Figure modified from Högler [246], with permission by Elsevier 2015.

\section{Osteoid \& Growth Plate \\ Mineralization}

Vitamin D - Calcium Intake

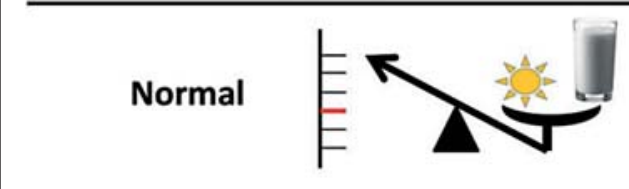

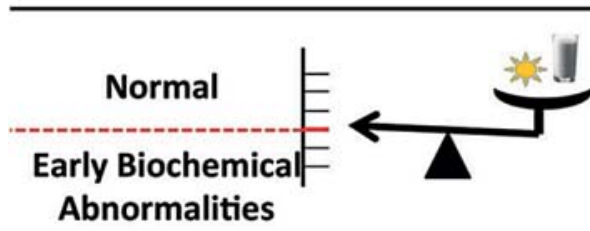

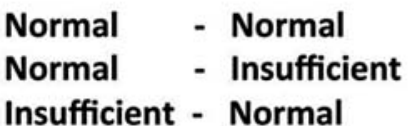

Insufficient - Normal

Normal - Deficient

Deficient - Normal

Insufficient - Insufficient large safety margin, the consensus group felt it prudent to use the concentration of $250 \mathrm{nmol} / \mathrm{l}$ as the recommended upper limit of serum $25 \mathrm{OHD}$ - even if symptomatic toxicity from RCTs has only been reported at levels $>500$ $\mathrm{nmol} / \mathrm{l}[32]$. In otherwise healthy infants, hypercalcemia and hypercalciuria in the absence of elevated 25OHD concentrations have been reported and may be related to genetic variation in vitamin D metabolism $[38,39]$.

\subsection{Dietary Calcium Intake to Prevent Rickets \\ 1.4.1 Recommendations}

- For infants 0-6 and 6-12 months of age, the adequate calcium intake is 200 and $260 \mathrm{mg} /$ day, respectively. $(1 \oplus \oplus \oplus)$

- For children over 12 months of age, dietary calcium intake of $<300 \mathrm{mg} /$ day increases the risk of rickets independently of serum $25 \mathrm{OHD}$ levels. $(1 \oplus \oplus \bigcirc)$

- For children over 12 months of age, the panel recommends the following classification of dietary calcium intake: $(1 \oplus \oplus \bigcirc)$

- Sufficiency, >500 mg/day

- Insufficiency, 300-500 mg/day

- Deficiency, $<300 \mathrm{mg} /$ day

\subsubsection{Evidence}

In developing countries where calcium intake is characteristically very low, with few or no dairy products, dietary calcium deficiency is the main cause of NR among children outside the infant age group.
In 2011, the IOM recommended adequate intakes of calcium for infants, children, and adults [16]. The adequate intake for infants was based on breast milk calcium content, which is 200 and $260 \mathrm{mg} /$ day for babies $0-6$ and 6-12 months of age, respectively. For children 1-18 years of age, the IOM set the daily calcium requirement at $700-1,300 \mathrm{mg} /$ day, depending on age [28]. There is, however, no true definition of dietary calcium deficiency without a reliable biomarker of calcium intake status, and there are little data to indicate what the lowest calcium intake is that prevents NR. Reports from Nigeria, India, and Bangladesh $[6,30,40-43]$ highlighted the role of low dietary calcium intake in the pathogenesis of NR among children. Although some of these children also had suboptimal 25OHD, others had values $>50$ $\mathrm{nmol} / \mathrm{l}$, which points to the interplay between calcium and vitamin $\mathrm{D}$ in the pathogenesis of NR (fig. 1). These studies suggest that in children $>12$ months of age, a dietary calcium intake of $<300 \mathrm{mg} /$ day significantly increases the risk of NR independently of serum $25 \mathrm{OHD}$ levels, and that at a daily intake of $>500 \mathrm{mg}$, no NR was seen.

\subsection{Vitamin D Deficiency and Fractures}

1.5.1 Recommendations

- Children with radiographically confirmed rickets have an increased risk of fracture. $(1 \oplus \oplus \bigcirc)$

- Children with simple vitamin D deficiency are not at an increased risk of fracture. $(1 \oplus \oplus \bigcirc)$ 


\subsubsection{Evidence}

Based on evidence from available observational studies and case reports, children with clinical, biochemical, and radiographic evidence of NR are at an increased risk of fracture. A retrospective study found that fractures occurred in 7 of $45(17.5 \%)$ infants and toddlers with NR, aged between 2 and 14 months [44]. However, fractures only occurred in those who were mobile and had severe radiographic evidence of rickets. Although none of the fractures were considered to be characteristic of nonaccidental injury (child abuse), 2 infants had lateral or anterior-lateral rib fractures. In a national survey in Canada, 11 of 108 cases of NR (11\%) had suffered fractures, although details on the bone sites and numbers of fractures were not provided [1]. Fractures also have been reported in cases or case series of NR in toddlers and adolescents [45-50], but details about the number, site, and type of fracture were absent.

It has been suggested that radiographic features of rickets may be mistaken for those characteristic of nonaccidental injury [51,52], but the necessary biochemical and radiographic data on the cases for validation of the authors' conclusions were absent. In addition, serum 25OHD levels are similar in infants with accidental and nonaccidental injuries [53]. Thus, simple vitamin D deficiency, that is vitamin D deficiency without biochemical or radiological signs of rickets, has not been associated with an increased fracture risk in infants and children.

\section{Prevention and Treatment of Nutritional Rickets and Osteomalacia}

\subsection{Vitamin D Supplementation for the Prevention of Rickets and Osteomalacia}

2.1.1 Recommendations

- $400 \mathrm{IU} /$ day $(10 \mu \mathrm{g})$ is adequate to prevent rickets and is recommended for all infants from birth to 12 months of age, independently of their mode of feeding. $(1 \oplus \oplus \oplus)$

- Beyond 12 months of age, all children and adults need to meet their nutritional requirement for vitamin $\mathrm{D}$ through diet and/or supplementation, which is at least $600 \mathrm{IU} /$ day $(15 \mu \mathrm{g})$, as recommended by the IOM. $(1 \oplus \oplus \oplus)$

\subsubsection{Evidence}

Few published studies have included the prevention of radiographic or clinical signs of rickets as an outcome. Consequently, we also reviewed studies that assessed the effect of different vitamin $\mathrm{D}$ supplementation regimens ${ }^{3}$ on 25OHD levels and other bone parameters (such as bone mineral density) with the goal of preventing NR by maintaining levels above the rachitic range, i.e. $>30 \mathrm{nmol} / \mathrm{l}$ [54].

In infants and children, 400 IU/day of vitamin D given as a supplement during infancy is sufficient to prevent radiographic signs of rickets in the short term (up to 12 months) [54]. Specifically, an RCT demonstrated that a vitamin D supplement of $400 \mathrm{IU} /$ day was sufficient to prevent radiographic signs of rickets at 6 months of age, even among infants born with vitamin D deficiency [25]. Similarly, no cases of radiographically confirmed rickets were seen after administration of $400 \mathrm{IU} /$ day of vitamin $\mathrm{D}$ for 12 months, whereas the incidence was $3.8 \%$ in Turkish infants and young children who did not receive supplementation [55]. In addition, no incident cases of radiographically confirmed rickets were reported in a 2-year surveillance study of Canadian infants who received 400 IU/day of vitamin D [1]. Worldwide, there have been no reports of radiographically confirmed rickets in infants or children receiving 400 IU on a regular, daily basis. Furthermore, this dose has been shown in RCTs to achieve 25OHD levels more frequently above the rachitic (severe deficiency) range compared to 100 or $200 \mathrm{IU} /$ day [25].

The prevention of vitamin $\mathrm{D}$ deficiency in the absence of NR was also briefly reviewed. In a double-blind RCT of infants without vitamin D deficiency (25OHD >50 $\mathrm{nmol} / \mathrm{l})$, the impact of $400,800,1,200$, and 1,600 IU of vitamin $\mathrm{D}_{3}$ per day was assessed [54]. Doses of $400 \mathrm{IU} /$ day maintained 25OHD levels $>50 \mathrm{nmol} / \mathrm{l}$ in $97 \%$ of infants after 12 months; doses of 800 and 1,200 IU/day were of no added benefit to bone mineral density parameters, and 1,600 IU/day raised concerns about potential toxicity. A study in infants with vitamin D deficiency $(25 \mathrm{OHD}$ $<25 \mathrm{nmol} / \mathrm{l}$ ) found that a single dose of 100,000 IU maintained 25OHD levels above $37.5 \mathrm{nmol} / \mathrm{l}$ for 3 months without hypercalcemia, whereas higher doses led to unacceptably high 25OHD levels [56].

Among infants and toddlers with 25OHD levels $<50$ $\mathrm{nmol} / \mathrm{l}$ for whom daily vitamin $\mathrm{D}$ supplementation may not be ideal, intermittent bolus doses of 50-100,000 IU every 3 months hold promise, although a comprehensive understanding of the safety and efficacy of this approach remains to be studied.

\footnotetext{
3 Note that the term 'supplementation' may be interpreted to mean additional vitamin D provided from supplements, general multivitamins, or food fortification. In the context of this article, vitamin D supplementation refers to vitamin $\mathrm{D}$ above that which is found in standard dietary sources, with the exception of fortified infant formula.
}

Munns et al. 
Table 2. Risk factors for NR and osteomalacia and their prevention

Maternal factors
Vitamin D deficiency
Dark skin pigmentation
Full body clothing cover
High latitude during winter/spring season
Other causes of restricted sun (UVB) exposure, e.g.
predominant indoor living, disability, pollution,
cloud cover
Low vitamin D diet
Low calcium diet
Poverty, malnutrition, special diets

Infant/childhood factors

Neonatal vitamin D deficiency secondary to maternal deficiency/vitamin D deficiency

Lack of infant supplementation with vitamin D

Prolonged breast-feeding without appropriate complementary feeding from 6 months

High latitude during winter/spring season

Dark skin pigmentation and/or restricted sun (UVB) exposure, e.g. predominant indoor living, disability, pollution, cloud cover

Low vitamin $\mathrm{D}$ diet

Low calcium diet

Poverty, malnutrition, special diets

Risk factors are prevented by:

Sun exposure (UVB content of sunlight depends on latitude and season)

Vitamin D supplementation

Strategic fortification of the habitual food supply

Normal calcium intake

\subsection{Target for Vitamin D Supplementation}

2.2.1 Recommendation

- In healthy children, routine $25 \mathrm{OHD}$ screening is not recommended, and consequently, no specific $25 \mathrm{OHD}$ threshold for vitamin $\mathrm{D}$ supplementation is targeted in this population. $(1 \oplus \oplus \oplus)$

\subsubsection{Evidence}

No studies have specifically examined the best monitoring approach once supplementation has been given to prevent vitamin D deficiency rickets. 25OHD is a reasonable monitoring parameter to ensure levels $>30-34 \mathrm{nmol} / 1$ for the prevention of NR. Biochemically, a fall in $25 \mathrm{OHD}$ concentration $<34 \mathrm{nmol} / 1$ is associated with rising $\mathrm{PTH}$ levels, but this intersection point depends on the prevailing calcium intake [7].

The frequent coexistence of dietary calcium deficiency and vitamin $\mathrm{D}$ deficiency alters the threshold for rickets development [57]. Similarly, monitoring 25OHD con-

centrations as a public health policy for all individuals is impractical; fortunately, high-risk groups can easily be identified based on clinical profile (table 2).

\subsection{Candidates for Preventative Vitamin D}

Supplementation beyond 12 Months of Age

2.3.1 Recommendations

In the absence of food fortification, vitamin D supplementation should be given to:

- Children with a history of symptomatic vitamin D deficiency requiring treatment $(1 \oplus \oplus \oplus)$

- Children and adults at high risk of vitamin D deficiency with factors or conditions that reduce synthesis or intake of vitamin $\mathrm{D}(1 \oplus \oplus \oplus)$

- Pregnant women (see section 3.1)

\subsubsection{Evidence}

Supplementation is a feasible and acceptable way to ensure adequate vitamin $\mathrm{D}$ intake independently of nutrition [58]. Consensus guidelines for vitamin D supplementation have been drafted from a variety of pediatric/ endocrine groups [16, 59-62]. Although there are numerous studies regarding vitamin $\mathrm{D}$ deficiency in pediatric populations and primary evaluations of the efficacy of various programs for supplementation of pregnant women, breast-feeding mothers, infants, children, and adolescents, there is more opinion than evidence on many aspects of this topic. However, there is strong, high-quality evidence that vitamin D supplementation should be provided for at-risk groups. All at-risk groups (table 2) are specifically vulnerable and, in the absence of food fortification, require supplementation.

Vitamin D fortification of infant formula is well established and recommended by all European countries, Australia, New Zealand, and the American Academy of Pediatrics [60]. Vitamin D fortification of milk is mandated in Canada, and 'enriched milk' is voluntarily fortified in the United States [63].

Children with chronic illnesses and conditions affecting vitamin $\mathrm{D}$ synthesis/absorption/metabolism may also benefit from supplementation and may require higher doses [58] but are not in the remit of this consensus on NR.

\subsection{Dose of Vitamin D and Calcium for the Treatment of Nutritional Rickets \\ 2.4.1 Recommendations}

- For the treatment of NR, the minimal recommended dose of vitamin $\mathrm{D}$ is $2,000 \mathrm{IU} /$ day $(50 \mu \mathrm{g})$ for a minimum of 3 months. $(1 \oplus \oplus \oplus)$ 
- Oral calcium, $500 \mathrm{mg} /$ day, either as dietary intake or supplements, should be routinely used in conjunction with vitamin $\mathrm{D}$ in the treatment regardless of age or weight. $(1 \oplus \oplus \oplus)$

\subsubsection{Evidence}

Most studies claim that the different doses commonly employed to treat vitamin D deficiency are safe, with hypercalcemia and/or hypercalciuria observed as a side effect only in a few individuals and usually seen in the 300,000 - to $600,000-\mathrm{IU}$ range [64]. In a small study of children with NR ( $\mathrm{n}=17)$, doses of 1,700-4,000 IU of vitamin $\mathrm{D}_{2}$ rapidly increased $25 \mathrm{OHD}$ concentrations within 1 week and normalized calcium, phosphate, and ALP levels at 10 weeks [65]. In another study in children aged 2-36 months with NR $(\mathrm{n}=19), 5,000-10,000 \mathrm{IU}$ of oral vitamin $\mathrm{D}_{3}$ and calcium $0.5-1.0 \mathrm{~g}$ daily normalized serum PTH, calcium, and phosphate within 3 weeks, although ALP levels remained elevated [66].

Simultaneous administration of calcium with vitamin $\mathrm{D}$ appears to be adequate and recommended by several studies $[67,68]$. In 123 Nigerian children with NR due to calcium deficiency, the combined end point of an ALP level $<350 \mathrm{U} / \mathrm{l}$ and radiographic evidence of near-complete healing of rickets was seen in a higher percentage of patients who received a combination of calcium and vitamin D (58\%) or calcium alone $(61 \%)$ than in those who received vitamin D alone (19\%) [5]. Similarly, in 67 Indian children with NR due to combined calcium and vitamin D deficiency, complete healing at 12 weeks was seen in a higher percentage with combined therapy (50\%) than with vitamin D (15.7\%) or calcium alone (11.7\%) [30].

Combined treatment is justified because studies have shown that the diet of children and adolescents with NR is generally low in both vitamin $\mathrm{D}$ and calcium $[5,6,30$, 69].

\subsection{Appropriate Route of Administration and Duration of Therapy}

2.5.1 Recommendations

- We recommend oral treatment, which more rapidly restores $25 \mathrm{OHD}$ levels than intramuscular (IM) treatment. $(1 \oplus \oplus \oplus)$

- For daily treatment, both $\mathrm{D}_{2}$ and $\mathrm{D}_{3}$ are equally effective. $(1 \oplus \oplus \oplus)$

- When single large doses are used, $\mathrm{D}_{3}$ appears to be preferable compared to $\mathrm{D}_{2}$ because the former has a longer half-life. $(1 \oplus \oplus \oplus)$
- Vitamin D treatment is recommended for a minimum of 12 weeks, recognizing that some children may require a longer treatment duration. $(1 \oplus \oplus \oplus)$

\subsubsection{Evidence}

Some studies compared IM and oral administration of vitamin $\mathrm{D}$, but most were conducted in adults and, therefore, may not be entirely relevant for children with NR. Oral or IM vitamin D was given to 24 normal volunteers (age, 50-78 years) in a dose of $600,000 \mathrm{IU}$ of $\mathrm{D}_{2}$ or $\mathrm{D}_{3}$ [70]. Peak levels of 25OHD were seen at 30 and 120 days in those given oral and IM treatment, respectively. Another study in 92 adults with $25 \mathrm{OHD}<75 \mathrm{nmol} / \mathrm{l}$ compared 300,000 IU vitamin $\mathrm{D}_{3}$ IM to $50,000 \mathrm{IU} \mathrm{D}_{3}$ orally given on 6 occasions over 3 months [71]. A higher proportion of subjects receiving oral treatment had $25 \mathrm{OHD}>75 \mathrm{nmol} / \mathrm{l}$ at 3 and 6 months than IM subjects.

One RCT in 61 children with NR compared a single IM dose of 600,000 IU vitamin $\mathrm{D}_{3}$ to a weekly oral dose of $60,000 \mathrm{IU} \mathrm{D}_{3}$ for 10 weeks [72]. There were no differences at 1,4 , and 12 weeks between groups in bone profiles, 25OHD concentrations, or side effects. A meta-analysis of studies comparing the administration of vitamin $\mathrm{D}_{2}$ and $\mathrm{D}_{3}$ concluded that, when given as bolus doses, vitamin $\mathrm{D}_{3}$ was more effective at raising $25 \mathrm{OHD}$ concentrations, but no significant differences were seen with daily doses [73].

There are no RCTs on the duration of treatment for children with NR, and most of the literature consists of review articles. The review commissioned by the PES recommends that daily oral treatment be given for 8-12 weeks [74]. Similar durations between 8 and 12 weeks of daily treatment are recommended in reviews from the United Kingdom $[75,76]$. A duration of 3 months is recommended in a consensus statement from Australia and New Zealand [77]. Given the limited evidence, we recommend a minimum treatment duration of 12 weeks to achieve a comprehensive healing and normalization of ALP, recognizing that some children may require a longer treatment.

Several studies explored the concept of 'stoss therapy,' i.e. the administration of a large dose given as a single dose or in divided doses over several days. This approach has been advocated for ease of use and compliance with therapy. Three different single oral doses $(150,000$, $300,000$, or $600,000 \mathrm{IU})$ in 56 Turkish children aged 3-36 months with NR did not affect the rate of improvement of rickets at 30 days [64].

However, 8 subjects ( 2 in the 300,000 -IU group, 6 in the 600,000-IU group) developed hypercalcemia. A recent study in India compared single oral doses of 300,000
Munns et al. 
Table 3. Treatment doses of vitamin D for nutritional rickets

\begin{tabular}{llll}
\hline Age & $\begin{array}{l}\text { Daily dose for } \\
90 \text { days, IU }\end{array}$ & $\begin{array}{l}\text { Single } \\
\text { dose, IU }\end{array}$ & $\begin{array}{l}\text { Maintenance } \\
\text { daily dose, IU }\end{array}$ \\
\hline$<3$ months & 2,000 & NA & 400 \\
$3-12$ months & 2,000 & 50,000 & 400 \\
$>12$ months to 12 years & $3,000-6,000$ & 150,000 & 600 \\
$>12$ years & 6,000 & 300,000 & 600 \\
\hline
\end{tabular}

$\mathrm{NA}=$ Not available. Reassess response to treatment after 3 months as further treatment may be required. Ensure a daily calcium intake of at least $500 \mathrm{mg}$. For conversion from IU to $\mu \mathrm{g}$, divide by 40 .

versus $600,000 \mathrm{IU}$ of vitamin $\mathrm{D}_{3}$ in 76 rachitic children aged 6 months to 5 years [78]. At 12 weeks, all children demonstrated radiographic healing with comparable decreases in ALP and PTH. However, hypercalcemia occurred in 5 children $(6.5 \%)-2$ receiving 300,000 IU and 3 receiving 600,000 IU. Several review articles advocate different recommendations with stoss therapy that are not supported by evidence [75-77]. The few studies comparing daily treatment to stoss therapy contained groups with different subject characteristics. Although we recommend daily treatment as the first line of management, we recognize that in some situations, stoss therapy may be more practical. Therefore, we provide vitamin $\mathrm{D}$ dose recommendations for both treatment options (table 3). Any treatment needs to be followed by supplementation (see sections 2.1 and 2.3).

\section{Prevention of Nutritional Rickets/Osteomalacia: Identification of Risk Factors}

\subsection{Dietary Practices and Nutrient Intakes among Mothers Associated with Nutritional Rickets in Infants} 3.1.1 Recommendations

- Maternal vitamin D deficiency should be avoided by ensuring that women of childbearing age meet the intakes of $600 \mathrm{IU} /$ day recommended by the IOM. $(1 \oplus \oplus \oplus)$

- Pregnant women should receive $600 \mathrm{IU} /$ day of vitamin $\mathrm{D}$, preferably as a combined preparation with other recommended micronutrients such as iron and folic acid. $(2 \oplus \oplus \bigcirc)$

\subsubsection{Evidence}

Maternal diet and nutrient intake as a predictor of infantile rickets have not been addressed in the literature as an a priori hypothesis. However, available data have been collected during vitamin $\mathrm{D}$ intervention studies, case studies, or case series in women during pregnancy.

Many cases of NR included data on maternal 25OHD and, in some cases, dietary information [79-81]. Neonatal vitamin $\mathrm{D}$ deficiency is always caused by maternal deficiency and can have life-threatening consequences such as hypocalcemic seizures and dilated cardiomyopathy in unsupplemented infants [11]. Hypocalcemia (see section 4.1.2) or other early biochemical signs of rickets (such as elevated ALP and PTH) are present before radiographic signs of NR occur in unsupplemented neonates and infants $[82,83]$. A high percentage of mothers of infants with symptomatic vitamin $\mathrm{D}$ deficiency are from highrisk groups who are vitamin D deficient and exclusively breast-feeding [11, 24, 83-85].

In a Canadian case series, 6 First Nation infants presented with hypocalcemic seizures within the first 30 days of life, with suspected or confirmed maternal vitamin $\mathrm{D}$ deficiency and a lack of supplementation during pregnancy [86]. All were formula fed, which suggests that although their intake of vitamin $\mathrm{D}$ would have been sufficient in normal circumstances, in these infants the oral vitamin D supply via formula milk was insufficient to treat their preexisting severe neonatal deficiency.

Prevention of maternal deficiency is critical, and all mothers should meet their nutritional requirement for vitamin $\mathrm{D}$, which is currently set at $600 \mathrm{IU} /$ day, although this value is not based on direct evidence from RCTs of vitamin D supplementation in pregnant women [28]. Potentially, a higher intake of vitamin $\mathrm{D}$ may be required to prevent both maternal and neonatal deficiency [87]. Prevention of congenital vitamin $\mathrm{D}$ deficiency is described in section 4.4.

\subsection{Early Feeding, Supplementation, Complementary Feeding, and Nutrient Intake Associated with Nutritional Rickets in Infants \\ 3.2.1 Recommendations}

- In addition to an intake of $400 \mathrm{IU} /$ day of vitamin D, complementary foods introduced no later than 26 weeks should include sources rich in calcium. $(1 \oplus \oplus \oplus)$

- An intake of at least $500 \mathrm{mg} /$ day of elemental calcium must be ensured during childhood and adolescence. $(1 \oplus \oplus \oplus)$ 


\subsubsection{Evidence}

There is abundant, yet low-quality evidence from multiple case reports, case series [11, 48, 49, 88], and observational studies $[1,2,45,50,85,89-99]$ that exclusive breast-feeding without vitamin $\mathrm{D}$ supplementation is a major risk factor for NR in infants. Furthermore, prolonged breast-feeding with late introduction of complementary feeding is associated with NR in infants not receiving vitamin D supplements [26, 100-105]. Abundant observational data [55, 106-111] and an RCT [25] suggest that infants receiving vitamin $\mathrm{D}$ supplementation in the first year of life are not at risk of developing NR. Evidence for providing $400 \mathrm{IU} /$ day vitamin $\mathrm{D}$ to infants is presented in section 2.1.

Evidence primarily from developing countries demonstrates that traditional diets low in calcium cause NR [30, 43, 69, 93, 112-114]. Therefore, special diets during infancy such as those that avoid milk and dairy products, those using soy or rice milk that are not specifically designed for infants, and/or vegan and macrobiotic diets may predispose infants to NR [115-120]. Recommendations on sufficient calcium intake are presented in section 1.4 .

\subsection{Association of Sunlight Exposure to Nutritional Rickets}

3.3.1 Recommendations

- Because ultraviolet $B(\mathrm{UVB})$ rays trigger the epidermal synthesis of previtamin $\mathrm{D}_{3}$, restricted exposure to sun increases the risk of vitamin $\mathrm{D}$ deficiency and NR. $(1 \oplus \oplus \oplus)$

- Environmental factors such as latitude, season, time of day, cloud cover, and pollution affect the availability of UVB, whereas personal factors such as time spent outdoors, skin pigmentation, skin coverage, age, body composition, and genetics affect the dose response to UVB exposure and circulating 25OHD. $(2 \oplus \oplus \bigcirc)$

- No safe threshold of UV exposure allows for sufficient vitamin $\mathrm{D}$ synthesis across the population without increasing skin cancer risk. $(2 \oplus \oplus \bigcirc)$

\subsubsection{Evidence}

Solar radiation (UVB band of $290-315 \mathrm{~nm}$ ) stimulates synthesis of previtamin $\mathrm{D}$ from epidermal 7-dehydrocholesterol, which isomerizes to cholecalciferol and is subsequently metabolized to $25 \mathrm{OHD}$. Sun exposure increases circulating 25OHD [121-123]. Assuming UVB availability, an individual's capacity to synthesize vitamin D increases with longer epidermal exposure. How- ever, exposure can be affected by environmental factors such as latitude, altitude, season, time of day, cloud cover, and air quality [123-129] as well as personal factors such as occupation, lifestyle, culture such as clothing, and preference which may modify the time spent outdoors and/or the surface area of skin exposed to sunlight [130-133]. Finally, the dose response of circulating $25 \mathrm{OHD}$ to cutaneous UVB exposure is dependent on skin pigmentation, age, body composition, genetic factors, and baseline 25OHD levels, among others [121, 131, 134-138].

Abundant global observational data report an association between restricted epidermal exposure and NR as a consequence of vitamin D deficiency [85, 139-143]. UV radiation causes skin cancer, and exposure to UV radiation from sunlight and artificial sources early in life elevates the risk of developing skin cancer [144]. Without firm evidence to account for variations in age, skin color, latitude, time of day, and time of year, it is currently impractical to provide prescriptive advice on safe solar exposure to the population as a whole. All risk factors are summarized in table 2 .

\section{Prevention of Osteomalacia during Pregnancy and Lactation and Congenital Rickets}

\subsection{The Relationship between Vitamin D during Pregnancy and Infant Growth and Bone Mass \\ 4.1.1 Recommendations}

- Pregnant women should receive 600 IU/day of supplemental vitamin $\mathrm{D}$. This will ensure adequacy of maternal 25OHD, especially in women at risk of deficiency, to prevent elevated cord blood ALP, increased fontanelle size, neonatal hypocalcemia and congenital rickets, and to improve dental enamel formation. $(2 \oplus \oplus \bigcirc)$

- There is little evidence that maternal supplementation with vitamin $\mathrm{D}$ will protect or improve birth anthropometry $(2 \oplus \oplus \bigcirc)$, and there is no evidence that supplementation with vitamin $\mathrm{D}$ will protect or improve short- or long-term growth or bone mass accretion. $(2 \oplus \oplus \bigcirc)$

\subsubsection{Evidence}

There is moderate evidence that low maternal vitamin D status during pregnancy is associated with elevated cord blood ALP and larger fontanelle size at birth [145, 146]. Moderate to strong evidence from 2 RCTs [145, 147], 2 controlled trials [148, 149], and 1 observational
Munns et al. 
Fig. 2. Double-blind RCTs have shown that maternal intakes of 1,000-6,400 IU/day of vitamin $\mathrm{D}$ are associated with increased breast milk vitamin D concentrations [156, $168,169,171]$. Lines of similar color represent the same study, and the legend provides the vitamin $\mathrm{D}$ supplementation dose (IU/day unless otherwise stated). Oberhelman et al. [171] reported milk concentrations of cholecalciferol only.

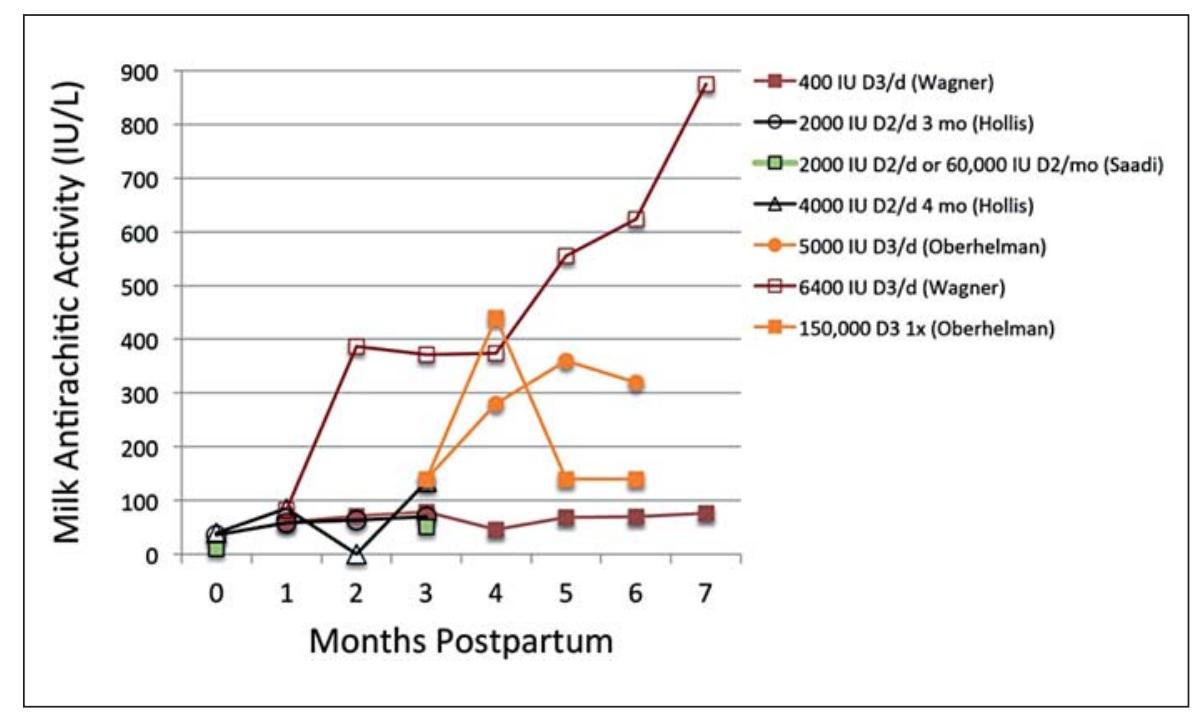

study [150] indicated that low maternal vitamin D status during pregnancy increases the risk of neonatal hypocalcemia; however, a smaller RCT and a controlled trial did not support these findings [146, 151]. A single large controlled trial suggests that vitamin D supplementation during pregnancy improves dental enamel formation of offspring [148].

There are conflicting data about the association between maternal vitamin D status during pregnancy and birth anthropometry. Three RCTs of moderate to high quality using daily dose or single high-dose regimens did not find an association [151-153], whereas 2 controlled trials of moderate-grade evidence found a positive association [146, 147]. Three low- to high-quality RCTs did not find any difference in birth anthropometry in offspring of mothers supplemented with $400,2,000$, or 4,000 IU/day; none of the studies had a placebo group [87, 154, 155].

There are inconsistent data on the association between maternal serum 25OHD levels and linear growth during the first year of life $[152,156-158]$ and insufficient to weak evidence for an association between maternal serum 25OHD levels and bone mass or density at birth $[150,159-162]$ or in later childhood [158, 163, 164].

\subsection{The Effect of Calcium Supplementation during Pregnancy on Infant Bone Mass}

4.2.1 Recommendation

- Pregnant women do not need calcium intakes above recommended nonpregnant intakes to improve neonatal bone. $(1 \oplus \oplus \oplus)$

\subsubsection{Evidence}

Calcium supplementation studies in pregnancy have not had congenital or neonatal rickets as an outcome, but 3 RCTs of maternal calcium supplementation during pregnancy measured neonatal bone [165-167]. These RCTs were conducted in West Africa where typical dietary calcium intakes are $250-300 \mathrm{mg} /$ day [165], in the United States with an average intake of about 2,000 mg/ day [166], and in a multicenter World Health Organization study in populations with dietary calcium intake of approximately $600 \mathrm{mg} /$ day (Argentina, Peru, India, Egypt, Vietnam, South Africa) [167]. Maternal calcium supplementation had no effect on neonatal bone mineral assessed by dual-energy X-ray absorptiometry in the Gambian and US studies, except in the latter study in the offspring of women in the lowest quintile of dietary calcium intake ( $<600 \mathrm{mg} /$ day). There was no effect of maternal calcium supplementation on neonatal or infant anthropometry, a finding consistent with observational studies.

\subsection{Influence of Calcium or Vitamin D}

Supplementation in Pregnancy or Lactation on Breast Milk Calcium or Vitamin D

\subsubsection{Recommendations}

- Lactating women should ensure they meet the dietary recommendations for vitamin D (600 IU/day) for their own needs, but not for the needs of their infant. $(1 \oplus \oplus \oplus)$ 
Fig. 3. Double-blind RCTs have shown that maternal serum 25OHD concentrations are increased with vitamin D supplementation [169, 171, 174, 182]. Most trials began supplementation shortly after birth. Markers of similar color represent the same study, and the legend provides the vitamin D supplementation dose (in IU/day unless otherwise stated). $1 \mathrm{ng} / \mathrm{ml}=2.5 \mathrm{nmol} / \mathrm{l}$. $\mathrm{Wtr}=$ Winter; Sum $=$ summer.

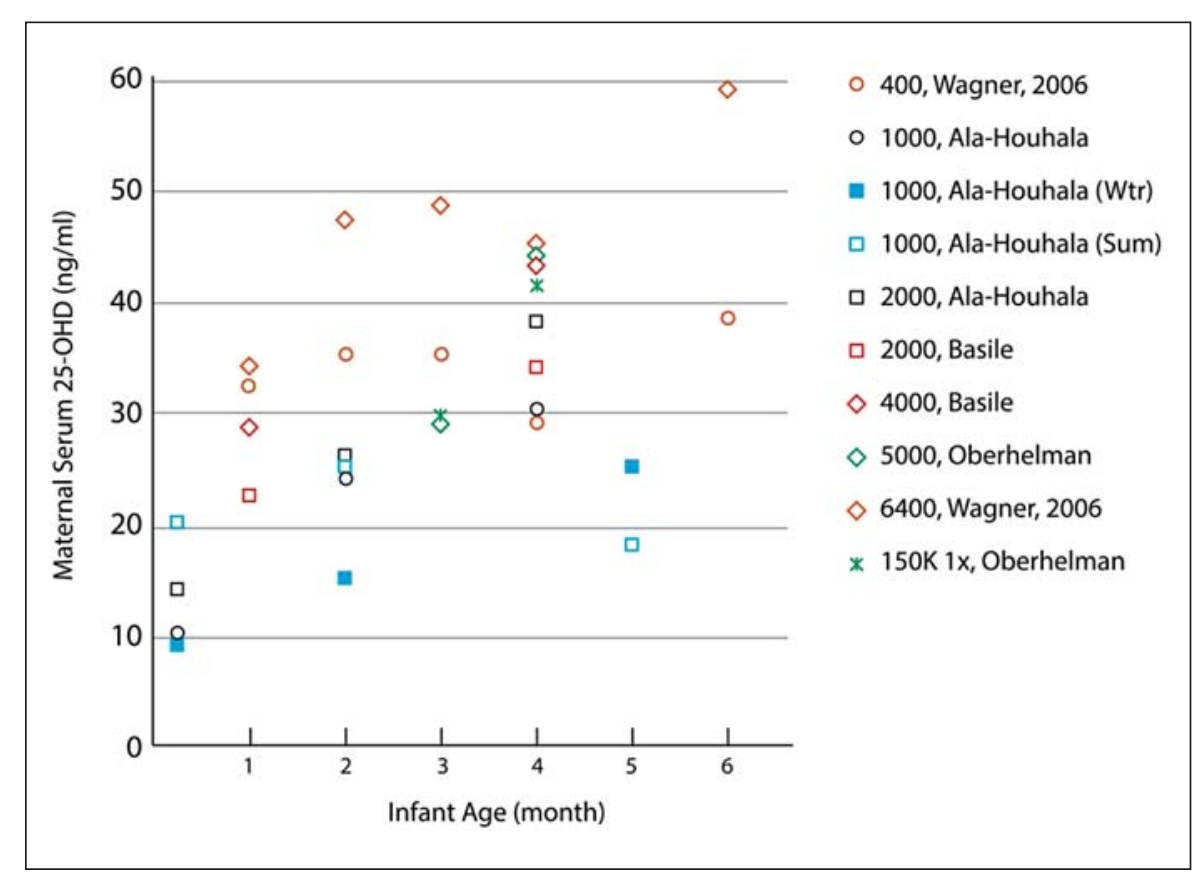

- Lactating women should not take high amounts of vitamin $\mathrm{D}$ as a means of supplementing their infant. $(2 \oplus \oplus \bigcirc)$

- Pregnant and lactating women should meet the recommended intakes of calcium. Maternal calcium intake during pregnancy or lactation is not associated with breast milk calcium concentrations. $(1 \oplus \oplus \oplus)$

\subsubsection{Evidence}

Maternal vitamin D intake during lactation correlates with milk vitamin D activity. Several double-blind RCTs found that high maternal intakes of vitamin D $(2,000,4,000$, and 6,400 IU/day) were associated with a higher breast milk vitamin D concentration (fig. 2) [168-171].

Supplementing mothers with high amounts of vitamin $\mathrm{D}$ has been suggested as a means of increasing both maternal (fig. 3) and infant serum 25OHD concentrations [172-175]. Maternal vitamin D intakes up to 4,000 IU/ day are likely safe during pregnancy and lactation [16]. However, the finding that infants of mothers supplemented with 2,000 IU/day or more have similar serum $25 \mathrm{OHD}$ concentrations as infants receiving $400 \mathrm{IU} /$ day (fig. 4), as well as safety concerns, and our own recommendation that all infants receive 400 IU vitamin D per day lead us to advise that mothers should take recom- mended amounts (600 IU/day) rather than higher doses of vitamin D.

Maternal calcium intake during pregnancy or lactation does not influence breast milk calcium concentrations. Only 1 observational study found a weak association between maternal calcium intakes during pregnancy and breast milk calcium level at day 40 (mature milk) [176]. Numerous studies, including 2 RCTs [177, 178] and 2 observational studies $[179,180]$, have not found a relationship between maternal calcium intake and breast milk calcium concentrations.

No studies have investigated the effect of maternal vitamin D intake during pregnancy on either milk calcium or vitamin D concentrations. Two double-blind RCTs found that maternal serum $25 \mathrm{OHD}$ concentration or maternal intake of vitamin D (up to 4,000 IU/day) during lactation was not associated with milk calcium concentrations $[181,182]$.

\subsection{Causes and Therapy of Congenital Rickets \\ 4.4.1 Recommendation}

- Supplementing mothers with $600 \mathrm{IU} /$ day of vitamin D and ensuring they receive recommended calcium intakes, or appropriate therapy of maternal conditions predisposing to hypocalcemia or vitamin D deficiency, prevents congenital rickets. $(2 \oplus \bigcirc \bigcirc)$ DOI: $10.1159 / 000443136$
Munns et al. 


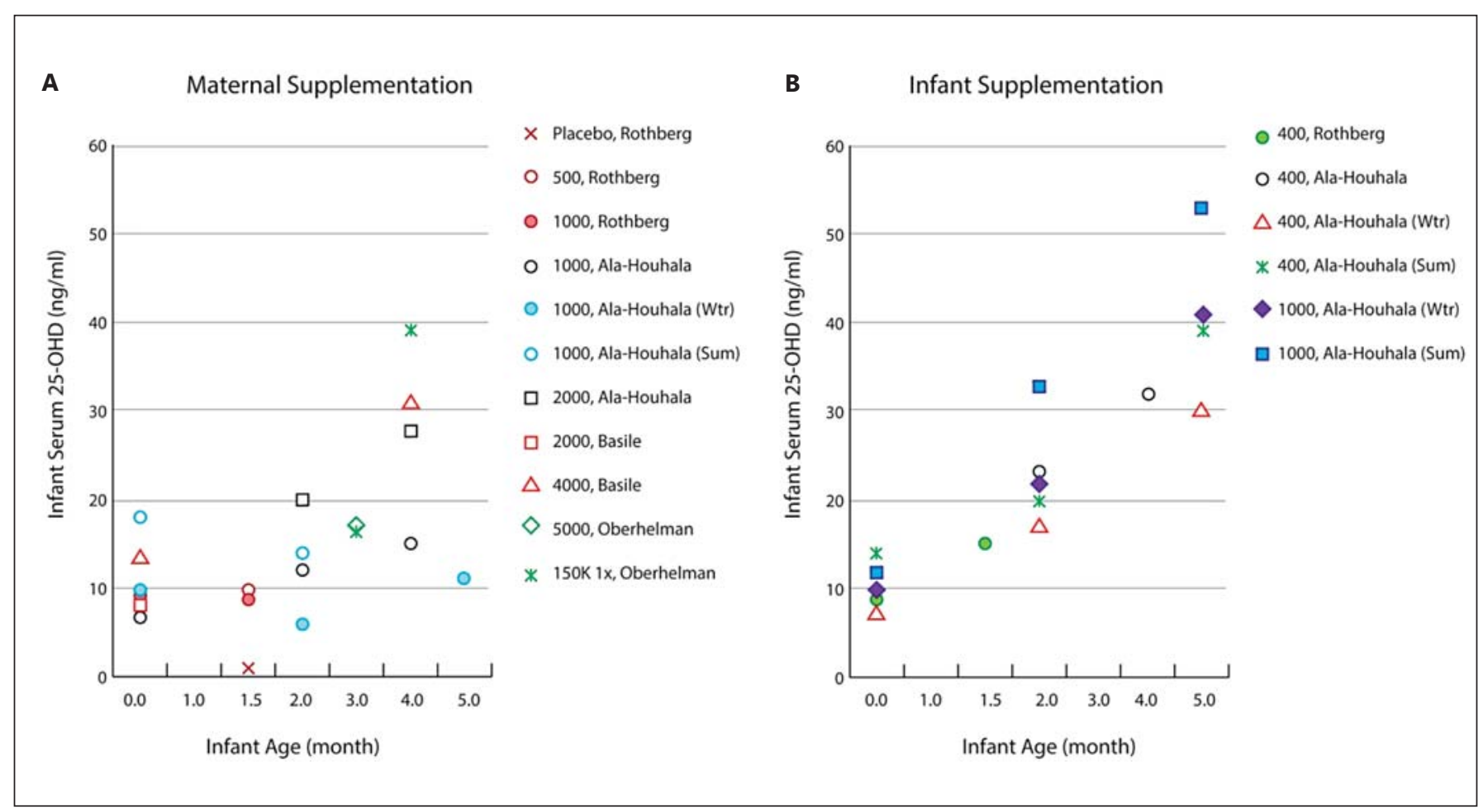

Fig. 4. Infant serum $25 \mathrm{OHD}$ concentrations by age in RCTs where either the mother was supplemented with vitamin D (A) or the infant was supplemented (B) [171, 173, 175, 182]. Markers of similar color represent the same study, and the legend provides the vitamin D supplementation dose (in IU/day unless otherwise stated). $1 \mathrm{ng} /$ $\mathrm{ml}=2.5 \mathrm{nmol} / \mathrm{l}$. Wtr $=$ Winter; Sum $=$ summer.

\subsubsection{Evidence}

Approximately 80 cases of congenital rickets, defined as babies presenting within the first 4 weeks of life with biochemical and radiographic signs of rickets, have been described in the medical literature. Typically, mothers of babies with congenital rickets have osteomalacia with severe vitamin $\mathrm{D}$ deficiency, low calcium intake, and hypocalcemia at delivery and had not taken vitamin D supplementation during pregnancy [83, 183-197]. In rare cases, congenital rickets can occur when mothers have had severe prolonged hypocalcemia not primarily caused by vitamin $\mathrm{D}$ deficiency such as poorly treated hypoparathyroidism [198-201], renal failure [202-206], received phosphate-containing enemas [207], or iatrogenic hypermagnesemia [208].

The mechanisms for the development of congenital rickets remain poorly understood, especially how diminished maternal calcium supply as the common primary maternal abnormality in all cases affects fetal mineralization. Clearly, congenital rickets only occurs in extreme metabolic situations. It is fair to state that all reported cases of congenital rickets could have been prevented by vitamin $\mathrm{D}$ supplementation, normal calcium intake during pregnancy, and adequate therapy of maternal conditions associated with prolonged hypocalcemia or vitamin D deficiency. Evidence is very limited on the therapy for congenital rickets, but rickets is generally responsive to vitamin $\mathrm{D}$ with or without calcium supplementation.

\section{Assessing the Burden of Nutritional Rickets and Public Health Strategies for Prevention}

\subsection{Assessment of Disease Burden}

\subsubsection{Recommendations}

- The prevalence of rickets should be determined by population-based samples, by case reports from sentinel centers, or by mandatory reporting. $(1 \oplus \oplus \oplus)$

- Screening for NR should be based on clinical features, followed by radiographic confirmation of suspected cases. $(1 \oplus \oplus \oplus)$ 
- Population-based screening with serum 25OHD, serum ALP, or radiographs is not indicated. $(1 \oplus \oplus \oplus)$

\subsubsection{Evidence}

NR has been increasingly reported in high- and lowincome countries [55, 209-213]. Using different methodology, the incidence of NR has been reported as 2.9, 4.9, 7.5, and 24 per 100,000 in Canada [1], Australia [2], the United Kingdom [3], and the United States [99], respectively. Many studies are hospital based but provide additional insight into the burden of NR. Infants with NR may present with hypocalcemic seizures. The incidence of dilated cardiomyopathy associated with NR and hypocalcemia is unknown, but it is potentially the deadliest and most economically costly complication of NR [11]. The methods used for the diagnosis of NR in case reports [102] and small to large case series [104, 214-217] are widely variable, and many lack radiographic confirmation [209]. Physician-based surveys can estimate the burden of disease, but few have been done $[1,2]$. Populationbased studies provide the most accurate assessment of the disease burden [3, 99, 211, 218-221]. Despite differing methodologies, published reports indicate the greatest burden of NR is in Africa, Asia, and the Middle East due to sun avoidance or dietary calcium insufficiency [209, 213].

Even high-income countries have observed a resurgence of NR, mainly among immigrants of African, Asian, or Middle-Eastern origin. This overall increase in the incidence of NR in high-income countries corresponds to an increase in the number of individuals in ethnic minority, immigrant, and refugee groups $[1-4,99,222]$. The incidence among established Caucasian populations is stable or decreasing. In regions with a low prevalence of $\mathrm{NR}$, inclusion of NR as a reportable disease is potentially the most cost-effective means of case identification and surveillance $[1,2,4,99,222]$.

Measurement of serum 25OHD is useful for the diagnosis of vitamin D deficiency in NR, but not for population screening [223, 224]. Raised serum ALP has been used as a screening tool for NR [225]. However, acute illness, drugs, liver disease, growth spurts, and transient hyperphosphatasemia of infancy and childhood can all elevate ALP values. Because of the invasiveness of venipuncture, high cost, and low positive predictive values, serum ALP and 25OHD cannot be recommended for population screening. Although radiographs of the wrists and knees provide definitive confirmation of active rickets [226], radiation exposure precludes recommending screening radiographs in asymptomatic children.

\subsection{Public Health Strategies for Rickets Prevention} 5.2.1 Recommendations

- Universally supplement all infants with vitamin D from birth to 12 months of age, independently of their mode of feeding. Beyond 12 months, supplement all groups at risk and pregnant women. Vitamin D supplements should be incorporated into childhood primary health care programs along with other essential micronutrients and immunizations $(1 \oplus \oplus \oplus)$, and into antenatal care programs along with other recommended micronutrients. $(2 \oplus \oplus 0)$

- Recognize NR, osteomalacia, and vitamin D and calcium deficiencies as preventable global public health problems in infants, children, and adolescents. $(1 \oplus \oplus \oplus)$

- Implement rickets prevention programs in populations with a high prevalence of vitamin D deficiency or limited vitamin $\mathrm{D}$ and/or calcium intakes and in groups of infants and children at risk of rickets. $(1 \oplus \oplus \oplus)$

- Monitor adherence to recommended vitamin D and calcium intakes and implement surveillance for NR. $(1 \oplus \oplus \oplus)$

- Fortify staple foods with vitamin D and calcium, as appropriate, based on dietary patterns. Food fortification can prevent rickets and improve vitamin $\mathrm{D}$ status of infants, children, and adolescents if appropriate foods are used and sufficient fortification is provided, if fortification is supported by relevant legislation, and if the process is adequately monitored. Indigenous food sources of calcium should be promoted or subsidized in children. $(1 \oplus \oplus \oplus)$

- Promote addressing the public health impact of vitamin D deficiency as both a clinical and a public health issue. $(1 \oplus \oplus \oplus)$

\subsubsection{Evidence}

5.2.2.1 Vitamin D Supplementation. Infants aged 0-12 months and adolescents are at an increased risk of NR and osteomalacia from vitamin $\mathrm{D}$ deficiency due to rapid growth. Vitamin D is found in a limited number of foods, and dietary intakes apart from fortified foods have little impact on overall vitamin D status. Programs that deliver micronutrient supplements provide the fastest improvement in micronutrient status of individuals or targeted populations [227, 228].

5.2.2.2 Food Fortification with Vitamin D. Food fortification of commonly consumed staple foods safely provides adequate intake to prevent deficiency at minimal cost. Mandatory fortification of staple foods with vitamin $\mathrm{D}$ and calcium ensures nutritional adequacy [229]. After 
vitamin $\mathrm{D}$ fortification of milk in North America and of milk, margarine, and cereals in the United Kingdom, the prevalence of NR dramatically declined, so much so that it was considered almost eradicated [16, 63, 228].

Studies in adults and children highlight the need for appropriate foods [230] to be adequately fortified and consumed by the at-risk segments of the population [231] so that vitamin $\mathrm{D}$ intakes of most members of a population approach dietary recommendations $[232,233]$. Because vitamin $\mathrm{D}$ fortification of foods rich in calcium is optimal for bone health, dairy products are commonly fortified. In countries where dairy products are not widely consumed, flour, margarine, cooking oil, or soy-based foods can be fortified with vitamin D.

Although several studies have assessed the effectiveness of vitamin $\mathrm{D}$ fortification of food to increase 25OHD concentrations in different age groups and communities, relatively few fortification studies have targeted children. A systematic review and meta-analysis concluded from food-based RCTs that vitamin D-fortified foods increase serum 25OHD and reduce the prevalence of deficiency $(<30 \mathrm{nmol} / \mathrm{l})$ in adults, provided appropriate vehicles are chosen based on analysis of habitual diet [234]. Fortification of chupatty flour $(6,000 \mathrm{IU} / \mathrm{kg})$ raised $25 \mathrm{OHD}$ from approximately $12.5 \mathrm{nmol} / 1$ to approximately $48 \mathrm{nmol} / \mathrm{l}$ in children over a 6-month period [235]. Fortification of fluid milk and margarine was estimated to increase vitamin $\mathrm{D}$ intake in 4-year-old children from 176 to $360 \mathrm{IU} /$ day (4.4 to $9 \mu \mathrm{g} /$ day) and 25OHD concentrations from 55 to $65 \mathrm{nmol} / \mathrm{l}$ [236]. Milk fortification has also been a successful strategy to improve the vitamin D status of schoolchildren in India [237]. Fortification and supplementation requirements may vary with population exposure to sunshine (see section 3) [238].

5.2.2.3 Food Fortification with Calcium. Inadequate dietary calcium intake is a risk factor for NR in children over the age of 12 months with low dairy product intake, a common situation in low-income countries. The IOM recommends a calcium intake of $500 \mathrm{mg}$ /day in children aged 1-3 years when children are at the greatest risk of NR, based on calcium retention in absorption studies [16]. In populations with low dairy intake such as in Africa and parts of Asia, indigenous food sources of calcium or fortification of staple foods with calcium can provide adequate calcium intake in children $[213,239]$. Calcium salts can be used to fortify infant formulas, complementary foods, and staple food in areas where dairy intake is low. Calcium carbonate for food fortification is available at very low cost [227].

Food fortification effectively increased dietary calcium intakes by using calcium-fortified laddoos in the diet of underprivileged Indian toddlers [240] and by calcium fortification of cereal for 7- to 12-year-old children [241]. More than 1,100 foods are calcium fortified in the United States, yet dairy food makes up more than $65 \%$ of adolescents' calcium intake [242]. In the United Kingdom, calcium fortification of flour is an important source of calcium intake ( $16 \%$ of total) for young adolescent girls [243]. There are limited data from studies on calcium fortification or the acceptability of dietary diversification to include locally available and affordable calcium-rich foods in developing countries. Periodic monitoring for NR is important to determine the effectiveness of fortification and/or supplementation programs in preventing NR.

5.2.2.4 Health Promotion. Education of medical providers and organizations, health insurers, policy makers, governments, public health officials, and the general public is vital to address the public health issue of NR and vitamin $\mathrm{D}$ deficiency. They should be provided with guidelines on the importance of adequate vitamin $\mathrm{D}$ and calcium intakes in children, adolescents, and pregnant and lactating women [244]. National and global public health promotion strategies are essential to raise professional and community awareness, and global action to protect all children from vitamin $\mathrm{D}$ and calcium deficiency is imperative.

\subsection{Economic Cost/Benefits of Prevention Programs \\ 5.3.1 Recommendation}

- The cost-effectiveness of supplementation and food fortification programs needs further study. $(1 \oplus \oplus \bigcirc)$

\subsubsection{Evidence}

Very weak evidence supports a policy of providing vitamin D supplementation to Asian children in the United Kingdom for the first 2 years of life [245]. However, this report had methodological limitations that preclude any conclusions.

Urgent research is required to model the cost-effectiveness of alternative vitamin D supplementation strategies and food fortification programs. Future economic models should include:

- Resources associated with different supplementation strategies

- Indirect costs of treatment and complications

- Resource use of current practice

- Effectiveness of different approaches

- Expected adherence

- Outcomes such as quality of life associated with 25OHD levels, and

- Health care costs of disease caused by both skeletal and extraskeletal effects of vitamin D deficiency 
Costs of vitamin D supplementation and/or fortification programs will differ depending on the target 25OHD level and population characteristics. Subgroup analyses targeting high-risk groups, such as people with darkly pigmented skin, limited sun exposure, and low calcium intakes, should be conducted.

\section{Conclusion}

Vitamin D deficiency should be considered a major global public health priority. NR can have severe consequences, including death from cardiomyopathy or obstructed labor, myopathy, seizures, pneumonia, lifelong deformity and disability, impaired growth, and pain. NR is the 'tip of the iceberg', and its resurgence indicates widespread vitamin $\mathrm{D}$ deficiency with important public health implications. NR and osteomalacia are fully preventable disorders that are on the rise worldwide and should be regarded as a global epidemic. We advocate for the eradication of NR and osteomalacia through vitamin D supplementation of all infants, pregnant women, and individuals from high-risk groups and the implementation of international food fortification programs to ensure nutritional sufficiency of vitamin $\mathrm{D}$ and calcium for the whole population. This consensus document provides policy makers with a reference framework to work toward the global eradication of rickets.

\section{Appendix: Affiliations of Consensus Group Members}

Magda Aguiar, Health Economics Unit, University of Birmingham, Birmingham, UK

Navoda Atapattu, Lady Ridgeway Hospital, Colombo, Sri Lanka Vijayalakshmi Bhatia, Department of Endocrinology, Sanjay Gandhi Postgraduate Institute of Medical Sciences, Uttar Pradesh, India

Christian Braegger, Division of Gastroenterology and Nutrition and Children's Research Center, University Children's Hospital, Zurich, Switzerland

Gary Butler, Department of Paediatric and Adolescent Endocrinology, University College London Hospital, London, UK

Hamilton Cassinelli, Endocrinology Division, Ricardo Gutierrez Children's Hospital, Buenos Aires, Argentina

Linda A. DiMeglio, Section of Pediatric Endocrinology/Diabetology, Riley Hospital for Children at Indiana University Health, Indianapolis, Ind., USA

Emma Frew, Health Economics Unit, University of Birmingham, Birmingham, UK

Junfen Fu, Division of Endocrinology, Children's Hospital of Zhejiang University School of Medicine, Hangzhou, China

Gail Goldberg, Nutrition and Bone Health Research Group, Medical Research Council Human Nutrition Research, Elsie Widdowson Laboratory, Cambridge, UK
Wolfgang Högler, Department of Endocrinology and Diabetes, Birmingham Children's Hospital; Institute of Metabolism and System's Research, University of Birmingham, Birmingham, UK

Elina Hyppönen, School of Population Health and Sansom Research Institute, University of South Australia, and South Australian Health and Medical Research Institute, Adelaide, S.A., Australia; Population Policy and Practice, University College London Institute of Child Health, London, UK

Hafsatu Wasagu Idris, Endocrinology and Gastroenterology Unit, Department of Paediatrics, Ahmadu Bello University Teaching Hospital, Zaria, Nigeria

Rajesh Khadgawat, Department of Endocrinology and Metabolism, All India Institute of Medical Sciences, New Delhi, India

Mairead Kiely, Vitamin D Research Group, School of Food and Nutritional Sciences, and Irish Centre for Fetal and Neonatal Translational Research (INFANT), University College Cork, Cork, Ireland

Jane Maddock, Institute of Child Health, University College London, London, UK

Outi Mäkitie, Children's Hospital, University of Helsinki and Helsinki University Hospital, Helsinki, Finland

Toshimi Michigami, Department of Bone and Mineral Research, Research Institute, Osaka Medical Center for Maternal and Child Health, Osaka, Japan

M. Zulf Mughal, Department of Paediatric Endocrinology, Royal Manchester Children's Hospital, Manchester, UK

Craig F. Munns, Department of Endocrinology and Diabetes, Children's Hospital at Westmead, Sydney, N.S.W., Australia

Abiola Oduwole, College of Medicine University of Lagos, Lagos, Nigeria

Keiichi Ozono, Department of Pediatrics, Osaka University Graduate School of Medicine, Osaka, Japan

John M. Pettifor, Medical Research Council/Wits Developmental Pathways for Health Research Unit, Department of Paediatrics, University of the Witwatersrand, Johannesburg, South Africa

Pawel Pludowski, Department of Biochemistry, Radioimmunology, and Experimental Medicine, Children's Memorial Health Institute, Warsaw, Poland

Lorna Ramos-Abad, University of the Philippines College of Medicine, Manila, The Philippines

Lars Sävendahl, Department of Women's and Children's Health, Karolinska Institutet, Stockholm, Sweden

Anju Seth, Division of Pediatric Endocrinology, Lady Hardinge Medical College and Kalawati Saran Children's Hospital, New Delhi, India

Nick Shaw, Department of Endocrinology and Diabetes, Birmingham Children's Hospital, Birmingham, UK

Bonny L. Specker, Ethel Austin Martin Program, South Dakota State University, Brookings, S.Dak., USA

Tom D. Thacher, College of Medicine, Mayo Clinic, Rochester, Minn., USA

Dov Tiosano, Department of Pediatrics, Rambam Medical Center, Haifa, Israel

Ted Tulchinsky, Braun School of Public Health, Hebrew University-Hadassah, Jerusalem, Israel; Public Health Reviews, Brussels, Belgium

Leanne Ward, Department of Pediatrics, University of Ottawa, and Division of Endocrinology and Metabolism, Children's Hospital of Eastern Ontario, Ottawa, Ont., Canada 


\section{Acknowledgments}

Editorial support was provided by Sally Farrand. This guideline was produced by ESPE, PES, SLEP, ASPAE, ISPAE, CSPEM, JSPE, APEG, APPES, ESPGHAN, and other expert participants. The consensus was financially supported by the above societies and an educational grant (nonparticipatory) by Danone Nutricia.

\section{Disclosure Statement}

M.Z.M. has received honoraria and lecture fees from Nutricia and Alexion. T.D.T. is a consultant for Biomedical Systems. W.H. has received honoraria and lecture fees from Internis and Alexion. No other author has anything to disclose.

\section{References}

1 Ward LM, Gaboury I, Ladhani M, Zlotkin S: Vitamin D-deficiency rickets among children in Canada. CMAJ 2007;177:161-166.

2 Munns CF, Simm PJ, Rodda CP, et al: Incidence of vitamin $\mathrm{D}$ deficiency rickets among Australian children: an Australian Paediatric Surveillance Unit study. Med J Aust 2012;196: 466-468.

> Callaghan AL, Moy RJ, Booth IW, Debelle G, Shaw NJ: Incidence of symptomatic vitamin D deficiency. Arch Dis Child 2006;91:606607.

-4 Beck-Nielsen SS, Jensen TK, Gram J, Brixen $\mathrm{K}$, Brock-Jacobsen B: Nutritional rickets in Denmark: a retrospective review of children's medical records from 1985 to 2005 . Eur J Pediatr 2009;168:941-949.

5 Thacher TD, Fischer PR, Pettifor JM, et al: A comparison of calcium, vitamin $\mathrm{D}$, or both for nutritional rickets in Nigerian children. N Engl J Med 1999;341:563-568.

6 Balasubramanian K, Rajeswari J, Gulab, et al: Varying role of vitamin D deficiency in the etiology of rickets in young children vs adolescents in northern India. J Trop Pediatr 2003;49:201-206.

7 Atapattu N, Shaw N, Högler W: Relationship between serum 25-hydroxyvitamin $\mathrm{D}$ and parathyroid hormone in the search for a biochemical definition of vitamin $\mathrm{D}$ deficiency in children. Pediatr Res 2013;74:552-556.

8 Paxton GA, Teale GR, Nowson CA, et al: Vitamin D and health in pregnancy, infants, children and adolescents in Australia and New Zealand: a position statement. Med J Aust 2013;198:142-143.

9 Pettifor JM: Vitamin D deficiency and nutritional rickets in children; in Feldman D, Pike JW, Adams J (eds): Vitamin D, ed 3. London, Elsevier, 2011, pp 1107-1128.

10 Pettifor JM: Nutritional rickets; in Glorieux FH, Pettifor JM, Juppner H (eds): Pediatric Bone: Biology and Diseases, ed 2. Amsterdam, Elsevier, 2012, pp 625-654.

11 Maiya S, Sullivan I, Allgrove J, et al: Hypocalcaemia and vitamin $\mathrm{D}$ deficiency: an important, but preventable, cause of life-threatening infant heart failure. Heart 2008;94:581584.

12 Loudon I: Deaths in childbed from the eighteenth century to 1935. Med Hist 1986;30:141.
3 Swiglo BA, Murad MH, Schünemann HJ, et al: A case for clarity, consistency, and helpfulness: state-of-the-art clinical practice guidelines in endocrinology using the grading of recommendations, assessment, development, and evaluation system. J Clin Endocrinol Metab 2008;93:666-673.

14 Thacher TD, Clarke BL: Vitamin D insufficiency. Mayo Clin Proc 2011;86:50-60.

15 Tiosano D, Hochberg Z: Hypophosphatemia: the common denominator of all rickets. J Bone Miner Metab 2009;27:392-401.

16 Institute of Medicine: Dietary Reference Intakes for Calcium and Vitamin D. Washington, National Academies Press, 2011.

17 Carter GD: Accuracy of 25-hydroxyvitamin D assays: confronting the issues. Curr Drug Targets 2011;12:19-28.

18 Farrell CJ, Martin S, McWhinney B, Straub I, Williams P, Herrmann M: State-of-the-art vitamin D assays: a comparison of automated immunoassays with liquid chromatographytandem mass spectrometry methods. Clin Chem 2012;58:531-542.

19 Tai SS, Bedner M, Phinney KW: Development of a candidate reference measurement procedure for the determination of 25-hydroxyvitamin $\mathrm{D}_{3}$ and 25-hydroxyvitamin $\mathrm{D}_{2}$ in human serum using isotope-dilution liquid chromatography-tandem mass spectrometry. Anal Chem 2010;82:1942-1948.

20 Stepman HC, Vanderroost A, Van Uytfanghe $\mathrm{K}$, Thienpont L: Candidate reference measurement procedures for serum 25-hydroxyvitamin $\mathrm{D}_{3}$ and 25-hydroxyvitamin $\mathrm{D}_{2}$ by using isotope-dilution liquid chromatography-tandem mass spectrometry. Clin Chem 2011;57:441-448.

21 Sempos CT, Vesper HW, Phinney KW, Thienpont LM, Coates PM: Vitamin D Standardization Program (VDSP). Vitamin D status as an international issue: national surveys and the problem of standardization. Scand J Clin Lab Invest Suppl 2012;243:32-40.

22 Carter GD, Phinney KW: Assessing vitamin D status: time for a rethink? Clin Chem 2014; 60:809-811.

23 Yates AM, Bowron A, Calton L, et al: Interlaboratory variation in 25-hydroxyvitamin $\mathrm{D}_{2}$ and 25-hydroxyvitamin $\mathrm{D}_{3}$ is significantly improved if common calibration material is used. Clin Chem 2008;54:2082-2084.
24 Dawodu A, Agarwal M, Sankarankutty M, Hardy D, Kochiyil J, Badrinath P: Higher prevalence of vitamin $D$ deficiency in mothers of rachitic than nonrachitic children. J Pediatr 2005;147:109-111.

25 Specker BL, Ho ML, Oestreich A, et al: Prospective study of vitamin D supplementation and rickets in China. J Pediatr 1992;120:733-739.

26 Majid Molla A, Badawi MH, al-Yaish S, Sharma P, el-Salam RS, Molla AM: Risk factors for nutritional rickets among children in Kuwait. Pediatr Int 2000;42:280-284.

27 Molla AM, Al Badawi M, Hammoud MS, et al: Vitamin D status of mothers and their neonates in Kuwait. Pediatr Int 2005;47:649-652.

28 Ross AC, Manson JE, Abrams SA, et al: The 2011 report on dietary reference intakes for calcium and vitamin D from the Institute of Medicine: what clinicians need to know. J Clin Endocrinol Metab 2011;96:53-58.

29 Theodoratou E, Tzoulaki I, Zgaga L, Ioannidis JP: Vitamin D and multiple health outcomes: umbrella review of systematic reviews and meta-analyses of observational studies and randomised trials. BMJ 2014;348:g2035.

30 Aggarwal V, Seth A, Aneja S, et al: Role of calcium deficiency in development of nutritional rickets in Indian children: a case control study. J Clin Endocrinol Metab 2012;97:3461-3466.

-31 Benitez-Aguirre PZ, Wood NJ, Biesheuvel C, Moreira C, Munns CF: The natural history of vitamin $\mathrm{D}$ deficiency in African refugees living in Sydney. Med J Aust 2009;190:426-428.

32 Vogiatzi MG, Jacobson-Dickman E, DeBoer MD: Vitamin D supplementation and risk of toxicity in pediatrics: a review of current literature. J Clin Endocrinol Metab 2014;99: $1132-1141$.

33 Tau C, Ciriani V, Scaiola E, Acuña M: Twice single doses of 100,000 IU of vitamin D in winter is adequate and safe for prevention of vitamin $\mathrm{D}$ deficiency in healthy children from Ushuaia, Tierra Del Fuego, Argentina. J Steroid Biochem Mol Biol 2007;103:651-654.

34 Joshi R: Hypercalcemia due to hypervitaminosis D: report of seven patients. J Trop Pediatr 2009;55:396-398.

35 Barrueto F Jr, Wang-Flores HH, Howland MA, Hoffman RS, Nelson L: Acute vitamin D intoxication in a child. Pediatrics 2005; 116 : e453-e456.

-36 Bereket A, Erdogan T: Oral bisphosphonate therapy for vitamin $\mathrm{D}$ intoxication of the infant. Pediatrics 2003;111:899-901. 
-37 Kara C, Gunindi F, Ustyol A, Aydin M: Vitamin $\mathrm{D}$ intoxication due to an erroneously manufactured dietary supplement in seven children. Pediatrics 2014;133:e240-e244.

38 Maalouf J, Nabulsi M, Vieth R, et al: Shortand long-term safety of weekly high-dose vitamin $\mathrm{D}_{3}$ supplementation in school children. J Clin Endocrinol Metab 2008;93:2693-2701.

-39 Vanstone MB, Oberfield SE, Shader L, Ardeshirpour L, Carpenter TO: Hypercalcemia in children receiving pharmacologic doses of vitamin D. Pediatrics 2012;129:e1060-e1063.

40 Pettifor JM, Ross P, Wang J, Moodley G, Couper-Smith J: Rickets in children of rural origin in South Africa: is low dietary calcium a factor? J Pediatr 1978;92:320-324.

-41 Legius E, Proesmans W, Eggermont E, Vandamme-Lobaerts R, Bouillon R, Smet M: Rickets due to dietary calcium deficiency. Eur J Pediatr 1989;148:784-785.

42 Eyberg CJ, Pettifor JM, Moodley G: Dietary calcium intake in rural black South African children. The relationship between calcium intake and calcium nutritional status. Hum Nutr Clin Nutr 1986;40:69-74.

43 Okonofua F, Gill DS, Alabi ZO, Thomas M, Bell JL, Dandona P: Rickets in Nigerian children: a consequence of calcium malnutrition. Metabolism 1991;40:209-213.

44 Chapman T, Sugar N, Done S, Marasigan J, Wambold N, Feldman K: Fractures in infants and toddlers with rickets. Pediatr Radiol 2010; 40:1184-1189.

-45 Kreiter SR, Schwartz RP, Kirkman HN Jr, Charlton PA, Calikoglu AS, Davenport ML: Nutritional rickets in African American breast-fed infants. J Pediatr 2000;137:153157.

-46 Hazzazi MA, Alzeer I, Tamimi W, Al Atawi $\mathrm{M}, \mathrm{Al}$ Alwan I: Clinical presentation and etiology of osteomalacia/rickets in adolescents. Saudi J Kidney Dis Transpl 2013;24:938-941.

47 Agarwal A, Gulati D, Rath S, Walia M: Rickets: a cause of delayed walking in toddlers. Indian J Pediatr 2009;76:269-272.

-48 Bloom E, Klein EJ, Shushan D, Feldman KW: Variable presentations of rickets in children in the emergency department. Pediatr Emerg Care 2004;20:126-130.

-49 Senniappan S, Elazabi A, Doughty I, Mughal MZ: Case 2: fractures in under-6-monthold exclusively breast-fed infants born to immigrant parents: nonaccidental injury? (case presentation). Diagnosis: pathological fractures secondary to vitamin $\mathrm{D}$ deficiency rickets in under-6-months-old, exclusively breast-fed infants, born to immigrant parents. Acta Paediatr 2008;97:836-837, 992-993.

50 Mylott BM, Kump T, Bolton ML, Greenbaum LA: Rickets in the dairy state. WMJ 2004;103: 84-87.

51 Paterson CR: Vitamin D deficiency rickets simulating child abuse. J Pediatr Orthop 1981; 1:423-425.

52 Paterson CR: Vitamin D deficiency rickets and allegations of non-accidental injury. Acta Paediatr 2009;98:2008-2012.
53 Schilling S, Wood JN, Levine MA, Langdon $\mathrm{D}$, Christian CW: Vitamin D status in abused and nonabused children younger than 2 years old with fractures. Pediatrics 2011;127:835841.

54 Gallo S, Comeau K, Vanstone C, et al: Effect of different dosages of oral vitamin D supplementation on vitamin D status in healthy, breastfed infants: a randomized trial. JAMA 2013;309:1785-1792.

55 Beser E, Cakmakci T: Factors affecting the morbidity of vitamin $\mathrm{D}$ deficiency rickets and primary prevention. East Afr Med J 1994;71: 358-362.

- 56 Zeghoud F, Ben-Mekhbi H, Djeghri N, Garabédian $\mathrm{M}$ : Vitamin $\mathrm{D}$ prophylaxis during infancy: comparison of the long-term effects of three intermittent doses (15, 5, or $2.5 \mathrm{mg})$ on 25-hydroxyvitamin D concentrations. Am J Clin Nutr 1994;60:393-396.

57 Pettifor JM: Calcium and vitamin D metabolism in children in developing countries. Ann Nutr Metab 2014;64(suppl 2):15-22.

58 Holmlund-Suila E, Koskivirta P, Metso T, Andersson S, Mäkitie O, Viljakainen H: Vitamin $\mathrm{D}$ deficiency in children with a chronic illness - seasonal and age-related variations in serum 25-hydroxy vitamin D concentrations. PLoS One 2013;8:e60856.

59 Wagner CL, Greer FR: Prevention of rickets and vitamin $\mathrm{D}$ deficiency in infants, children, and adolescents. Pediatrics 2008; 122:11421152 .

60 Braegger C, Campoy C, Colomb V, et al: Vitamin D in the healthy European paediatric population. J Pediatr Gastroenterol Nutr 2013;56:692-701.

61 Holick MF, Binkley NC, Bischoff-Ferrari HA, et al: Evaluation, treatment, and prevention of vitamin D deficiency: an Endocrine Society clinical practice guideline. J Clin Endocrinol Metab 2011;96:1911-1930.

62 Vidailhet M, Mallet E, Bocquet A, et al: Vitamin D: still a topical matter in children and adolescents. A position paper by the Committee on Nutrition of the French Society of Paediatrics. Arch Pediatr 2012;19:316-328.

63 Calvo MS, Whiting SJ, Barton CN: Vitamin D fortification in the United States and Canada: current status and data needs. Am J Clin Nutr 2004;80:1710S-1716S.

-64 Cesur Y, Caksen H, Gündem A, Kirimi E, Odabaş D: Comparison of low and high dose of vitamin $\mathrm{D}$ treatment in nutritional vitamin D deficiency rickets. J Pediatr Endocrinol Metab 2003;16:1105-1109.

65 Markestad T, Halvorsen S, Halvorsen KS, Aksnes L, Aarskog D: Plasma concentrations of vitamin $\mathrm{D}$ metabolites before and during treatment of vitamin $\mathrm{D}$ deficiency rickets in children. Acta Paediatr Scand 1984;73:225-231.

66 Kruse K: Pathophysiology of calcium metabolism in children with vitamin D-deficiency rickets. J Pediatr 1995;126:736-741.
67 Kutluk G, Cetinkaya F, Başak M: Comparisons of oral calcium, high dose vitamin D and a combination of these in the treatment of nutritional rickets in children. J Trop Pediatr 2002;48:351-353.

68 Oginni LM, Sharp CA, Badru OS, Risteli J, Davie MW, Worsfold M: Radiological and biochemical resolution of nutritional rickets with calcium. Arch Dis Child 2003;88:812817

69 Thacher T, Glew RH, Isichei C, et al: Rickets in Nigerian children: response to calcium supplementation. J Trop Pediatr 1999;45: 202-207.

70 Cipriani C, Romagnoli E, Pepe J, et al: Longterm bioavailability after a single oral or intramuscular administration of $600,000 \mathrm{IU}$ of ergocalciferol or cholecalciferol: implications for treatment and prophylaxis. J Clin Endocrinol Metab 2013;98:2709-2715.

71 Zabihiyeganeh M, Jahed A, Nojomi M: Treatment of hypovitaminosis D with pharmacologic doses of cholecalciferol, oral vs intramuscular; an open labeled RCT. Clin Endocrinol (Oxf) 2013;78:210-216.

72 Mondal K, Seth A, Marwaha R, et al: A randomized controlled trial on safety and efficacy of single intramuscular versus staggered oral dose of 600,000 IU vitamin D in treatment of nutritional rickets. J Trop Pediatr 2014;60: 203-210.

73 Tripkovic L, Lambert H, Hart K, et al: Comparison of vitamin $\mathrm{D}_{2}$ and vitamin $\mathrm{D}_{3}$ supplementation in raising serum 25-hydroxyvitamin D status: a systematic review and metaanalysis. Am J Clin Nutr 2012;95:1357-1364.

74 Misra M, Pacaud D, Petryk A, Collett-Solberg PF, Kappy M: Vitamin D deficiency in children and its management: review of current knowledge and recommendations. Pediatrics 2008;122:398-417.

75 Pearce SH, Cheetham TD: Diagnosis and management of vitamin D deficiency. BMJ 2010;340:b5664

76 Shaw NJ, Mughal MZ: Vitamin D and child health. 2. Extraskeletal and other aspects. Arch Dis Child 2013;98:368-372.

77 Munns C, Zacharin MR, Rodda CP, et al: Prevention and treatment of infant and childhood vitamin D deficiency in Australia and New Zealand: a consensus statement. Med J Aust 2006;185:268-272.

78 Mittal H, Rai S, Shah D, et al: 300,000 IU or $600,000 \mathrm{IU}$ of oral vitamin $\mathrm{D}_{3}$ for treatment of nutritional rickets: a randomized controlled trial. Indian Pediatr 2014;51:265-272.

79 Elidrissy AT, Sedrani SH, Lawson DE: Vitamin $\mathrm{D}$ deficiency in mothers of rachitic infants. Calcif Tissue Int 1984;36:266-268.

80 Bhakhri BK, Debata PK: Nutritional rickets presenting with myelofibrosis. Indian J Pediatr 2010;77:1437-1439.

81 Brinsmead T, Frawley K, Conwell LS: Images in pediatric endocrinology: vitamin $\mathrm{D}$ deficiency rickets and other nutritional deficiencies in a 12-month-old infant. J Pediatr Endocrinol Metab 2011;24:13-14. 
82 Sanyal D, Raychaudhuri M: Infants with dilated cardiomyopathy and hypocalcemia. Indian J Endocrinol Metab 2013;17(suppl 1): S221-S223.

83 Soliman A, Salama H, Alomar S, Shatla E, Ellithy $\mathrm{K}$, Bedair E: Clinical, biochemical, and radiological manifestations of vitamin $\mathrm{D}$ deficiency in newborns presented with hypocalcemia. Indian J Endocrinol Metab 2013;17: 697-703.

84 Robinson PD, Högler W, Craig ME, et al: The re-emerging burden of rickets: a decade of experience from Sydney. Arch Dis Child 2006; 91:564-568.

85 Al-Atawi MS, Al-Alwan IA, Al-Mutair AN, Tamim HM, Al-Jurayyan NA: Epidemiology of nutritional rickets in children. Saudi J Kidney Dis Transpl 2009;20:260-265.

86 Gross ML, Tenenbein M, Sellers EA: Severe vitamin D deficiency in 6 Canadian First Nation formula-fed infants. Int J Circumpolar Health 2013;72:20244.

$>87$ Dawodu A, Saadi HF, Bekdache G, Javed Y, Altaye M, Hollis BW: Randomized controlled trial (RCT) of vitamin D supplementation in pregnancy in a population with endemic vitamin D deficiency. J Clin Endocrinol Metab 2013;98:2337-2346.

-88 Brown J, Nunez S, Russell M, Spurney C: Hypocalcemic rickets and dilated cardiomyopathy: case reports and review of literature. $\mathrm{Pe}$ diatr Cardiol 2009;30:818-823.

89 Ahmed I, Atiq M, Iqbal J, Khurshid M, Whittaker P: Vitamin D deficiency rickets in breastfed infants presenting with hypocalcaemic seizures. Acta Paediatr 1995;84:941-942.

90 Bachrach S, Fisher J, Parks J: An outbreak of vitamin $\mathrm{D}$ deficiency rickets in a susceptible population. Pediatrics 1979;64:871-877.

-91 Binet A, Kooh S: Persistence of vitamin D-deficiency rickets in Toronto in the 1990s. Can J Public Health 1996;87:227-230.

92 Cesur Y, Yuca SA, Kaya A, Yilmaz C, Bay A: Vitamin $\mathrm{D}$ deficiency rickets in infants presenting with hypocalcaemic convulsions. West Indian Med J 2013;62:201-204.

93 DeLucia MC, Mitnick ME, Carpenter TO: Nutritional rickets with normal circulating 25-hydroxyvitamin D: a call for reexamining the role of dietary calcium intake in North American infants. J Clin Endocrinol Metab 2003;88:3539-3545.

\$94 Haworth JC, Dilling LA: Vitamin-D-deficient rickets in Manitoba, 1972-1984. CMAJ 1986; 134:237-241.

95 Lazol JP, Cakan N, Kamat D: 10-year case review of nutritional rickets in Children's Hospital of Michigan. Clin Pediatr (Phila) 2008; 47:379-384.

96 Matsuo K, Mukai T, Suzuki S, Fujieda K: Prevalence and risk factors of vitamin D deficiency rickets in Hokkaido, Japan. Pediatr Int 2009;51:559-562.

97 Peng LF, Serwint JR: A comparison of breastfed children with nutritional rickets who present during and after the first year of life. Clin Pediatr (Phila) 2003;42:711-717.
98 Salama MM, El-Sakka AS: Hypocalcemic seizures in breastfed infants with rickets secondary to severe maternal vitamin D deficiency. Pak J Biol Sci 2010;13:437-442.

99 Thacher TD, Fischer PR, Tebben PJ, et al: Increasing incidence of nutritional rickets: a population-based study in Olmsted County, Minnesota. Mayo Clin Proc 2013;88:176183.

100 Akpede GO, Omotara BA, Ambe JP: Rickets and deprivation: a Nigerian study. J R Soc Promot Health 1999;119:216-222.

101 El Hag AI, Karrar ZA: Nutritional vitamin D deficiency rickets in Sudanese children. Ann Trop Paediatr 1995;15:69-76.

102 Kaper BP, Romness MJ, Urbanek PJ: Nutritional rickets: report of four cases diagnosed at orthopaedic evaluation. Am J Orthop 2000;29:214-218.

103 Kruger DM, Lyne ED, Kleerekoper M: Vitamin D deficiency rickets. A report on three cases. Clin Orthop Relat Res 1987;224:277283.

104 Mughal MZ, Salama H, Greenaway T, Laing I, Mawer EB: Lesson of the week: florid rickets associated with prolonged breast feeding without vitamin D supplementation. BM] 1999;318:39-40.

105 Siddiqui TS, Rai MI: Presentation and predisposing factors of nutritional rickets in children of Hazara Division. J Ayub Med Coll Abbottabad 2005;17:29-32.

106 Lerch C, Meissner T: Interventions for the prevention of nutritional rickets in term born children. Cochrane Database Syst Rev 2007;4:CD006164.

107 Ozkan B, Doneray H, Karacan M, et al: Prevalence of vitamin $\mathrm{D}$ deficiency rickets in the eastern part of Turkey. Eur J Pediatr 2009; 168:95-100.

108 Pedersen P, Michaelsen KF, Mølgaard C: Children with nutritional rickets referred to hospitals in Copenhagen during a 10-year period. Acta Paediatr 2003;92:87-90.

109 Robertson I: Survey of clinical rickets in the infant population in Cape Town, 19671968. S Afr Med J 1969;43:1072-1076.

110 Strand MA, Peng G, Zhang P, Lee G: Preventing rickets in locally appropriate ways: a case report from North China. Int Q Community Health Educ 2003;21:297-322.

-111 Tezer H, Siklar Z, Dallar Y, Doğankoç S: Early and severe presentation of vitamin $\mathrm{D}$ deficiency and nutritional rickets among hospitalized infants and the effective factors. Turk J Pediatr 2009;51:110-115.

112 Combs GF Jr, Hassan N, Dellagana N, et al: Apparent efficacy of food-based calcium supplementation in preventing rickets in Bangladesh. Biol Trace Elem Res 2008;121: 193-204.

113 Combs GF, Hassan N: The Chakaria food system study: household-level, case-control study to identify risk factor for rickets in Bangladesh. Eur J Clin Nutr 2005;59:12911301.
14 Rudolf M, Arulanantham K, Greenstein R: Unsuspected nutritional rickets. Pediatrics 1980;66:72-76.

115 Castile RG, Marks LJ, Stickler GB: Vitamin $\mathrm{D}$ deficiency rickets. Two cases with faulty infant feeding practices. Am J Dis Child 1975;129:964-966.

116 Curtis JA, Kooh SW, Fraser D, Greenberg ML: Nutritional rickets in vegetarian children. Can Med Assoc J 1983;128:150-152.

117 Fox AT, Du Toit G, Lang A, Lack G: Food allergy as a risk factor for nutritional rickets. Pediatr Allergy Immunol 2004;15:566-569.

118 Imataka G, Mikami T, Yamanouchi H, Kano K, Eguchi M: Vitamin D deficiency rickets due to soybean milk. J Paediatr Child Health 2004;40:154-155.

119 Miyako K, Kinjo S, Kohno H: Vitamin D deficiency rickets caused by improper lifestyle in Japanese children. Pediatr Int 2005;47: 142-146.

120 Barreto-Chang OL, Pearson D, Shepard WE, et al: Vitamin D-deficient rickets in a child with cow's milk allergy. Nutr Clin Pract 2010;25:394-398.

121 Holick MF: Environmental factors that influence the cutaneous production of vitamin D. Am J Clin Nutr 1995;61(suppl):638S645S.

122 Bogh M: Vitamin D production after UVB: aspects of UV-related and personal factors. Scand J Clin Lab Invest Suppl 2012;243:2431.

123 Webb AR, Kline L, Holick MF: Influence of season and latitude on the cutaneous synthesis of vitamin $\mathrm{D}_{3}$ : exposure to winter sunlight in Boston and Edmonton will not promote vitamin $\mathrm{D}_{3}$ synthesis in human skin. J Clin Endocrinol Metab 1988;67:373-378.

124 Agarwal KS, Mughal MZ, Upadhyay P, Berry JL, Mawer EB, Puliyel JM: The impact of atmospheric pollution on vitamin $\mathrm{D}$ status of infants and toddlers in Delhi, India. Arch Dis Child 2002;87:111-113.

125 Harris SS, Dawson-Hughes B: Seasonal changes in plasma 25-hydroxyvitamin D concentrations of young American black and white women. Am J Clin Nutr 1998;67: 1232-1236.

126 Petersen B, Wulf HC, Triguero-Mas M, et al: Sun and ski holidays improve vitamin D status, but are associated with high levels of DNA damage. J Invest Dermatol 2014;134: $2806-2813$

127 Richter K, Breitner S, Webb A, et al: Influence of external, intrinsic and individual behaviour variables on serum $25(\mathrm{OH}) \mathrm{D}$ in a German survey. J Photochem Photobiol B 2014;140:120-129.

128 Terushkin V, Bender A, Psaty EL, Engelsen $O$, Wang SQ, Halpern AC: Estimated equivalency of vitamin $D$ production from natural sun exposure versus oral vitamin D supplementation across seasons at two US latitudes. J Am Acad Dermatol 2010;62:929.e1e9. 
129 Holick MF: McCollum Award Lecture, 1994: vitamin D - new horizons for the 21st century. Am J Clin Nutr 1994;60:619-630.

130 Bodekær M, Petersen B, Thieden E, et al: UVR exposure and vitamin D in a rural population. A study of outdoor working farmers, their spouses and children. Photochem Photobiol Sci 2014;13:1598-1606.

$\checkmark 131$ Bogh MK, Schmedes AV, Philipsen PA, Thieden E, Wulf HC: Interdependence between body surface area and ultraviolet $B$ dose in vitamin $\mathrm{D}$ production: a randomized controlled trial. Br J Dermatol 2011;164: 163-169.

132 Kift R, Berry JL, Vail A, Durkin MT, Rhodes LE, Webb AR: Lifestyle factors including less cutaneous sun exposure contribute to starkly lower vitamin D levels in UK. South Asians compared with the white population. Br J Dermatol 2013;169:1272-1278.

-133 Thieden E, Philipsen PA, Heydenreich J, Wulf HC: UV radiation exposure related to age, sex, occupation, and sun behavior based on time-stamped personal dosimeter readings. Arch Dermatol 2004;140:197-203.

134 Diffey BL: Is casual exposure to summer sunlight effective at maintaining adequate vitamin D status? Photodermatol Photoimmunol Photomed 2010;26:172-176.

135 Farrar MD, Kift R, Felton SJ, et al: Recommended summer sunlight exposure amounts fail to produce sufficient vitamin D status in UK adults of South Asian origin. Am J Clin Nutr 2011;94:1219-1224.

-136 Farrar MD, Webb AR, Kift R, et al: Efficacy of a dose range of simulated sunlight exposures in raising vitamin D status in South Asian adults: implications for targeted guidance on sun exposure. Am J Clin Nutr 2013; 97:1210-1216.

137 MacLaughlin J, Holick MF: Aging decreases the capacity of human skin to produce vitamin $D_{3}$. J Clin Invest 1985;76:1536-1538.

138 Webb AR, Kift R, Durkin MT, et al: The role of sunlight exposure in determining the vitamin D status of the UK white adult population. Br J Dermatol 2010;163:1050-1055.

139 Al-Mustafa ZH, Al-Madan M, Al-Majid HJ, Al-Muslem S, Al-Ateeq S, Al-Ali AK: Vitamin $\mathrm{D}$ deficiency and rickets in the Eastern Province of Saudi Arabia. Ann Trop Paediatr 2007;27:63-67.

140 Haider N, Nagi AG, Khan KM: Frequency of nutritional rickets in children admitted with severe pneumonia. J Pak Med Assoc 2010; 60:729-732.

141 Ozkan B: Nutritional rickets. J Clin Res Pediatr Endocrinol 2010;2:137-143.

142 Pettifor JM: Vitamin D and/or calcium deficiency rickets in infants and children: a global perspective. Indian J Med Res 2008; 127: 245-249.

-143 Teotia SP, Teotia M: Nutritional bone disease in Indian population. Indian J Med Res 2008;127:219-228.
144 Balk SJ: Ultraviolet radiation: a hazard to children and adolescents. Pediatrics 2011; 127:e791-e817.

145 Brooke OG, Brown IR, Bone CD, et al: Vitamin D supplements in pregnant Asian women: effects on calcium status and fetal growth. Br Med J 1980;280:751-754.

146 Kalra P, Das V, Agarwal A, Kumar M, Ramesh V, Bhatia E: Effect of vitamin D supplementation during pregnancy on neonatal mineral homeostasis and anthropometry of the newborn and infant. Br J Nutr 2012;108: 1052-1058.

147 Marya RK, Rathee S, Dua V, Sangwan K: Effect of vitamin D supplementation during pregnancy on foetal growth. Indian J Med Res 1988;88:488-492.

148 Cockburn F, Belton NR, Purvis RJ, et al: Maternal vitamin $\mathrm{D}$ intake and mineral metabolism in mothers and their newborn infants. Br Med J 1980;281:11-14.

149 Delvin EE, Salle BL, Glorieux FH, Adeleine P, David LS: Vitamin D supplementation during pregnancy: effect on neonatal calcium homeostasis. J Pediatr 1986;109:328-334.

150 Congdon P, Horsman A, Kirby PA, Dibble J, Bashir T: Mineral content of the forearms of babies born to Asian and white mothers. $\mathrm{Br}$ Med J (Clin Res Ed) 1983;286:1233-1235.

151 Mallet E, Gügi B, Brunelle P, Hénocq A, Basuyau JP, Lemeur H: Vitamin D supplementation in pregnancy: a controlled trial of two methods. Obstet Gynecol 1986;68:300-304.

152 Brooke OG, Butters F, Wood C: Intrauterine vitamin $\mathrm{D}$ nutrition and postnatal growth in Asian infants. Br Med J (Clin Res Ed) 1981; 283:1024.

153 Yu CK, Sykes L, Sethi M, Teoh TG, Robinson S: Vitamin D deficiency and supplementation during pregnancy. Clin Endocrinol (Oxf) 2009;70:685-690.

154 Hollis BW, Johnson D, Hulsey TC, Ebeling M, Wagner CL: Vitamin D supplementation during pregnancy: double-blind, randomized clinical trial of safety and effectiveness. J Bone Miner Res 2011;26:2341-2357.

155 Wagner CL, McNeil R, Hamilton SA, et al: A randomized trial of vitamin D supplementation in 2 community health center networks in South Carolina. Am J Obstet Gynecol 2013;208:137.e1-e13.

156 Saadi HF, Dawodu A, Afandi BO, Zayed R, Benedict S, Nagelkerke N: Efficacy of daily and monthly high-dose calciferol in vitamin D-deficient nulliparous and lactating women. Am J Clin Nutr 2007;85:1565-1571.

-157 Leffelaar ER, Vrijkotte TG, van Eijsden M: Maternal early pregnancy vitamin D status in relation to fetal and neonatal growth: results of the multi-ethnic Amsterdam Born Children and their Development cohort. $\mathrm{Br}$ J Nutr 2010;104:108-117.

158 Javaid MK, Crozier SR, Harvey NC, Gale CR, Dennison EM, Boucher BJ: Maternal vitamin D status during pregnancy and childhood bone mass at age 9 years: a longitudinal study. Lancet 2006;367:36-43.
159 Weiler H, Fitzpatrick-Wong S, Veitch R, Kovacs H, Schellenberg J, McCloy U: Vitamin $\mathrm{D}$ deficiency and whole-body and femur bone mass relative to weight in healthy newborns. CMAJ 2005;172:757-761.

160 Viljakainen HT, Saarnio E, Hytinantti T, et al: Maternal vitamin D status determines bone variables in the newborn. J Clin Endocrinol Metab 2010;95:1749-1757.

161 Mahon P, Harvey N, Crozier S, Inskip H, Robinson S, Arden N: Low maternal vitamin D status and fetal bone development: cohort study. J Bone Miner Res 2010;25:14-19.

162 Ioannou C, Javaid MK, Mahon P, et al: The effect of maternal vitamin $\mathrm{D}$ concentration on fetal bone. J Clin Endocrinol Metab 2012; 97:E2070-E2077.

163 Lawlor DA, Wills AK, Fraser A, Sayers A, Fraser WD, Tobias JH: Association of maternal vitamin $\mathrm{D}$ status during pregnancy with bonemineral content in offspring: a prospective cohort study. Lancet 2013;381:2176-2183.

-164 Sayers A, Tobias J: Estimated maternal ultraviolet $\mathrm{B}$ exposure levels in pregnancy influence skeletal development of the child. J Clin Endocrinol Metab 2009;94:765-771.

165 Jarjou LM, Prentice A, Sawo Y, et al: Randomized, placebo-controlled, calcium supplementation study in pregnant Gambian women: effects on breast-milk calcium concentrations and infant birth weight, growth, and bone mineral accretion in the first year of life. Am J Clin Nutr 2006;83:657-666.

166 Koo WW, Walters JC, Esterlitz J, Levine RJ, Bush AJ, Sibai B: Maternal calcium supplementation and fetal bone mineralization. Obstet Gynecol 1999;94:577-582.

167 Villar J, Abdel-Aleem H, Merialdi M, et al: World Health Organization randomized trial of calcium supplementation among low calcium intake pregnant women. Am J Obstet Gynecol 2006;194:639-649.

168 Hollis BW, Wagner CL: Vitamin D requirements during lactation: high-dose maternal supplementation as therapy to prevent hypovitaminosis $\mathrm{D}$ for both the mother and the nursing infant. Am J Clin Nutr 2004; 80(suppl):1752S-1758S.

169 Wagner CL, Hulsey TC, Fanning D, Ebeling $\mathrm{M}$, Hollis BW: High-dose vitamin $\mathrm{D}_{3}$ supplementation in a cohort of breastfeeding mothers and their infants: a 6-month followup pilot study. Breastfeed Med 2006;1:5970.

170 Saadi HF, Dawodu A, Afandi B, et al: Effect of combined maternal and infant vitamin $D$ supplementation on vitamin D status of exclusively breastfed infants. Matern Child Nutr 2009;5:25-32.

171 Oberhelman SS, Meekins ME, Fischer PR, et al: Maternal vitamin D supplementation to improve the vitamin D status of breast-fed infants: a randomized controlled trial. Mayo Clin Proc 2013;88:1378-1387. 
172 Basile LA, Taylor SN, Wagner CL, Horst RL, $>186$ Russell JG, Hill LF: True fetal rickets. Br J Hollis BW: The effect of high-dose vitamin $\mathrm{D}$ supplementation on serum vitamin $\mathrm{D}$ levels and milk calcium concentration in lactating women and their infants. Breastfeed Med 2006;1:27-35.

173 Rothberg AD, Pettifor JM, Cohen DF, Sonnendecker EW, Ross FP: Maternal-infant vitamin D relationships during breast-feeding. J Pediatr 1982;101:500-503.

174 Ala-Houhala M: 25-Hydroxyvitamin D levels during breast-feeding with or without maternal or infantile supplementation of vitamin D. J Pediatr Gastroenterol Nutr 1985; $4: 220-226$.

175 Ala-Houhala M, Koskinen T, Terho A, Koivula T, Visakorpi J: Maternal compared with infant vitamin D supplementation. Arch Dis Child 1986;61:1159-1163.

-176 Ortega RM, Martínez RM, Quintas ME, López-Sobaler AM, Andrés P: Calcium levels in maternal milk: relationships with calcium intake during the third trimester of pregnancy. Br J Nutr 1998;79:501-507.

-177 Prentice A, Jarjou LM, Cole TJ, Stirling DM, Dibba B, Fairweather-Tait S: Calcium requirements of lactating Gambian mothers: effects of a calcium supplement on breastmilk calcium concentration, maternal bone mineral content, and urinary calcium excretion. Am J Clin Nutr 1995;62:58-67.

-178 Kalkwarf HJ, Specker BL, Bianchi DC, Ranz J, Ho M: The effect of calcium supplementation on bone density during lactation and after weaning. N Engl J Med 1997;337:523528.

-179 Vaughan LA, Weber CW, Kemberling SR: Longitudinal changes in the mineral content of human milk. Am J Clin Nutr 1979;32: 2301-2306.

$>180$ Kirksey A, Ernst JA, Roepke JL, Tsai TL: Influence of mineral intake and use of oral contraceptives before pregnancy on the mineral content of human colostrum and of more mature milk. Am J Clin Nutr 1979;32: 30-39.

181 Prentice A, Yan L, Jarjou LM, et al: Vitamin D status does not influence the breast-milk calcium concentration of lactating mothers accustomed to a low calcium intake. Acta Paediatr 1997;86:1006-1008.

-182 Basile LA, Taylor SN, Wagner CL, Horst RL, Hollis BW: The effect of high-dose vitamin $\mathrm{D}$ supplementation on serum vitamin $\mathrm{D}$ levels and milk calcium concentration in lactating women and their infants. Breastfeed Med 2006;1:27-35.

$>183$ Begum R, Coutinho ML, Dormandy TL, Yudkin S: Maternal malabsorption presenting as congenital rickets. Lancet 1968;1: 1048-1052.

184 Ford JA: Proceedings: aetiology of Asian rickets and osteomalacia in the United Kingdom. Arch Dis Child 1973;48:827-828.

-185 Moncrieff M, Fadahunsi TO: Congenital rickets due to maternal vitamin $\mathrm{D}$ deficiency. Arch Dis Child 1974;49:810-811.
Radiol 1974;47:732-734.

187 Zeidan S, Bamford M: Congenital rickets with maternal pre-eclampsia. J R Soc Med 1984;77:426-427.

188 Park W, Paust H, Kaufmann HJ, Offermann G: Osteomalacia of the mother - rickets of the newborn. Eur J Pediatr 1987;146:292293.

189 Mittal M, Kumar A, Ramji S, Narula S, Thirupuram S: Congenital rickets. Indian Pediatr 1990;27:857-859.

190 Teotia M, Teotia SP, Nath M: Metabolic studies in congenital vitamin $\mathrm{D}$ deficiency rickets. Indian J Pediatr 1995;62:55-61.

191 Sann L, David L, Frederich A: Congenital rickets. Study of the evolution of secondary hyperparathyroidism. Acta Paediatr Scand 1977;66:323-327.

192 Ramavat L: Vitamin D deficiency rickets at birth in Kuwait. Indian J Pediatr 1999;66: 37-43.

193 Innes AM, Seshia MM, Prasad C, et al: Congenital rickets caused by maternal vitamin $\mathrm{D}$ deficiency. Paediatr Child Health 2002;7: 455-458.

194 Maiyegun SO, Malek AH, Devarajan LV, Dahniya MH: Severe congenital rickets secondary to maternal hypovitaminosis D: a case report. Ann Trop Paediatr 2002;22: 191-195.

195 Mohapatra A, Sankaranarayanan K, Kadam SS, Binoy S, Kanbur WA, Mondkar JA: Congenital rickets. J Trop Pediatr 2003;49:126127.

196 Erdeve O, Atasay B, Arsan S, Siklar Z, Ocal G, Berberoğlu M: Hypocalcemic seizure due to congenital rickets in the first day of life. Turk J Pediatr 2007;49:301-303.

197 Tiwari S, Kumar R, Singla S, Dudeja A, Nangia S, Saili A: Congenital rickets presenting as refractory respiratory distress at birth. Indian J Pediatr 2014;81:800-802.

198 Gradus D, Le Roith D, Karplus M, Zmora E, Grief M, Bar-Ziv J: Congenital hyperparathyroidism and rickets: secondary to maternal hypoparathyroidism and vitamin $\mathrm{D}$ deficiency. Isr J Med Sci 1981;17:705-708.

199 Glass EJ, Barr DG: Transient neonatal hyperparathyroidism secondary to maternal pseudohypoparathyroidism. Arch Dis Child 1981;56:565-568.

200 Loughead JL, Mughal Z, Mimouni F, Tsang RC, Oestreich AE: Spectrum and natural history of congenital hyperparathyroidism secondary to maternal hypocalcemia. Am J Perinatol 1990;7:350-355.

201 Demirel N, Aydin M, Zenciroglu A, et al: Hyperparathyroidism secondary to maternal hypoparathyroidism and vitamin $\mathrm{D}$ deficiency: an uncommon cause of neonatal respiratory distress. Ann Trop Paediatr 2009;29:149-154.

202 Kirk J: Congenital rickets - a case report. Aust Paediatr J 1982;18:291-293.
203 Levin TL, States L, Greig A, Goldman HS: Maternal renal insufficiency: a cause of congenital rickets and secondary hyperparathyroidism. Pediatr Radiol 1992;22:315-316.

-204 Wang LY, Hung HY, Hsu CH, Shih SL, Lee YJ: Congenital rickets - a patient report. J Pediatr Endocrinol Metab 1997;10:437-441.

205 Al-Senan K, al-Alaiyan S, al-Abbad A, LeQuesne G: Congenital rickets secondary to untreated maternal renal failure. J Perinatol 2001;21:473-475.

206 Samson GR: Skeletal dysplasias with osteopenia in the newborn: the value of alkaline phosphatase. J Matern Fetal Neonatal Med 2005; 17:229-231.

207 Rimensberger P, Schubiger G, Willi U: Connatal rickets following repeated administration of phosphate enemas in pregnancy: a case report. Eur J Pediatr 1992;151:54-56.

208 Lamm CI, Norton KI, Murphy RJ, Wilkins IA, Rabinowitz JG: Congenital rickets associated with magnesium sulfate infusion for tocolysis. J Pediatr 1988;113:1078-1082.

209 Thacher TD, Fischer PR, Strand MA, Pettifor JM: Nutritional rickets around the world: causes and future directions. Ann Trop Paediatr 2006;26:1-16.

210 Bener A, Al-Ai M, Hoffmann GF: Vitamin $\mathrm{D}$ deficiency in healthy children in a sunny country: associated factors. Int J Food Sci Nutr 2009;60(suppl 5):60-70.

211 Harris NS, Crawford PB, Yangzom Y, Pinzo L, Gyaltsen P, Hudes M: Nutritional and health status of Tibetan children living at high altitudes. N Engl J Med 2001;344:341347.

212 Muhe L, Lulseged S, Mason KE, Simoes EA: Case-control study of the role of nutritional rickets in the risk of developing pneumonia in Ethiopian children. Lancet 1997;349: 1801-1804.

213 Thacher TD, Fischer PR, Isichei CO, Zoakah AI, Pettifor JM: Prevention of nutritional rickets in Nigerian children with dietary calcium supplementation. Bone 2012;50:10741080.

214 Fischer PR, Rahman A, Cimma JP, et al: Nutritional rickets without vitamin $\mathrm{D}$ deficiency in Bangladesh. J Trop Pediatr 1999;45: 291-293.

-215 Thacher TD, Fischer PR, Pettifor JM, Lawson JO, Manaster BJ, Reading JC: Radiographic scoring method for the assessment of the severity of nutritional rickets. J Trop Pediatr 2000;46:132-139.

216 Cesur Y, Doğan M, Ariyuca S, et al: Evaluation of children with nutritional rickets. J Pediatr Endocrinol Metab 2011;24:35-43.

217 Weisberg P, Scanlon KS, Li R, Cogswell ME: Nutritional rickets among children in the United States: review of cases reported between 1986 and 2003. Am J Clin Nutr 2004; 80(suppl):1697S-1705S.

218 Uush T: Prevalence of classic signs and symptoms of rickets and vitamin $\mathrm{D}$ deficiency in Mongolian children and women. J Steroid Biochem Mol Biol 2013;136:207-210. 
219 Bener A, Hoffmann G: Nutritional rickets among children in a sun rich country. Int $J$ Pediatr Endocrinol 2010;2010:410502.

220 Tserendolgor U, Mawson JT, Macdonald AC, Oyunbileg M: Prevalence of rickets in Mongolia. Asia Pac J Clin Nutr 1998;7:325328.

221 Underwood P, Margetts B: High levels of childhood rickets in rural North Yemen. Soc Sci Med 1987;24:37-41.

222 Goldacre M, Hall N, Yeates DG: Hospitalisation for children with rickets in England: a historical perspective. Lancet 2014;383:597598.

223 Gordon CM, Williams AL, Feldman HA, et al: Treatment of hypovitaminosis D in infants and toddlers. J Clin Endocrinol Metab 2008;93:2716-2721.

224 Strand MA, Perry J, Jin M, et al: Diagnosis of rickets and reassessment of prevalence among rural children in northern China. Pediatr Int 2007;49:202-209.

225 Taylor JA, Geyer LJ, Feldman KW: Use of supplemental vitamin D among infants breastfed for prolonged periods. Pediatrics 2010;125:105-111.

226 Thacher TD, Fischer PR, Pettifor JM, Lawson JO, Isichei CO, Chan GM: Case-control study of factors associated with nutritional rickets in Nigerian children. J Pediatr 2000; 137:367-373.

227 World Health Organization: Guidelines on Food Fortification with Micronutrients. Geneva, World Health Organization, 2006.

228 Allen L: New approaches for designing and evaluating food fortification programs. J Nutr 2006;136:1055-1058.
229 Flynn M: Recommendations for a National Policy on Vitamin D Supplementation for Infants in Ireland. Dublin, Food Safety Authority of Ireland, 2007.

230 Engle-Stone R, Ndjebayi AO, Nankap M, Brown K: Consumption of potentially fortifiable foods by women and young children varies by ecological zone and socio-economic status in Cameroon. J Nutr 2012;142:555565.

231 Babu US, Calvo MS: Modern India and the vitamin D dilemma: evidence for the need of a national food fortification program. Mol Nutri Food Res 2010;54:1134-1147.

232 Kiely M, Black L: Dietary strategies to maintain adequacy of circulating 25-hydroxyvitamin D concentrations. Scand J Clin Lab Invest Suppl 2012;243:14-23.

233 Lamberg-Allardt C, Brustad M, Meyer $\mathrm{H}$, Steingrimsdottir L: Vitamin D - a systematic literature review for the 5th edition of the Nordic Nutrition Recommendations. Food Nutr Res 2013;3:57.

234 Black LJ, Seamans KM, Cashman KD, Kiely M: An updated systematic review and metaanalysis of the efficacy of vitamin $\mathrm{D}$ food fortification. J Nutr 2012;142:1102-1108.

235 Pietrek J, Preece MA, Windo J, et al: Prevention of vitamin-D deficiency in Asians. Lancet 1976;i:1145-1148.

236 Piirainen T, Laitinen K, Isolauri E: Impact of national fortification of fluid milks and margarines with vitamin $\mathrm{D}$ on dietary intake and serum 25-hydroxyvitamin D concentration in 4-year-old children. Eur J Clin Nutr 2007; 61:123-128.

237 Khadgawat R, Marwaha RK, Garg MK, et al: Impact of vitamin D fortified milk supplementation on vitamin D status of healthy school children aged 10-14 years. Osteoporos Int 2013;24:2335-2343.
238 Kumar J, Muntner P, Kaskel FJ, Hailpern SM, Melamed ML: Prevalence and associations of 25-hydroxyvitamin D deficiency in US children: NHANES 2001-2004. Pediatrics 2009; 124:e362-e370.

239 Thacher TD, Fischer PR, Pettifor JM: Vitamin D treatment in calcium-deficiency rickets: a randomised controlled trial. Arch Dis Child 2014;99:807-811.

240 Ekbote VH, Khadilkar AV, Chiplonkar SA, Hanumante NM, Khadilkar VV, Mughal MZ: A pilot randomized controlled trial of oral calcium and vitamin D supplementation using fortified laddoos in underprivileged Indian toddlers. Eur J Clin Nutr 2011;65:440-446.

241 Nieman DC, Henson DA, Sha W: Ingestion of micronutrient fortified breakfast cereal has no influence on immune function in healthy children: a randomized controlled trial. Nutr J 2011;10:36.

242 Rafferty K, Watson P, Lappe J: The selection and prevalence of natural and fortified calcium food sources in the diets of adolescent girls. J Nutr Educ Behav 2011;43:96-102.

243 Hackett AF, Rugg-Gunn AJ, Allinson M, Robinson CJ, Appleton DR, Eastoe JE: The importance of fortification of flour with calcium and the sources of $\mathrm{Ca}$ in the diet of 375 English adolescents. Br J Nutr 1984;51:193-197.

244 Greer F: Defining vitamin D deficiency in children: beyond $25-\mathrm{OH}$ vitamin D serum concentrations. Pediatrics 2009;124:14711473.

245 Zipitis CS, Markides GA, Swann IL: Vitamin D deficiency: prevention or treatment? Arch Dis Child 2006;91:1011-1014.

246 Högler W: Complications of vitamin D deficiency from the foetus to the infant: one cause, one prevention, but who's responsibility? Best Pract Res Clin Endocrinol Metab 2015;29:385-398. 